\title{
Los expolios del paisaje monumental y la arquitectura hispana de los siglos VII al XI. Reflexiones sobre el proceso constructivo de San Miguel de Escalada
}

Isidro BANGO TORVISO

Universidad Autónoma de Madrid

A la memoria de Fernando Galván. El medievalista que tanto me ha enseñado. El amigo que nunca podré olvidar.

RESUMEN: El artículo ofrece una reinterpretación del epígrafe de 913, explicando que las obras realizadas son de carácter ornamental según expresa de manera muy clara la citada inscripción. A partir de este dato se realiza una nueva visión del proceso constructivo, señalando fases bien definidas que comienzan con el edificio de época visigoda. Se pone un especial énfasis en el reaprovechamiento de los materiales como característica fundamental en la arquitectura que define la repoblación del territorio durante los siglos IX al XI. Por último, se cuestiona el grupo de capiteles del pórtico como creación del siglo $\mathrm{X}$, siendo un material procedente del expolio de un edificio anterior.

Palabras clave: Arquitectura de repoblación, reaprovechamiento de materiales, capiteles, mozárabe.

ABSTRACT: The article offers a reinterpretation of the epigraph of 913, explaining that the executed works are of ornamental character as it is expressed very clearly by the mentioned inscription. From this information a new vision of the constructive process is made, indicating well defined phases that begin with the building of visigothic period. A special emphasis is put in the materials reutilization as a fundamental characteristic in the architecture that defines the repopulation of the territory during the IXth to XIth centuries. Finally, the group of capitals of the arcade as a creation of the 10th century is questioned, being a material from a pillage of a previous building.

Key words: Architecture of repopulation, materials reutilization, capitals, Mozarab.

El grupo de iglesias situadas en el amplio marco geográfico denominado Valle del Duero, cuya cronología, aunque no de manera unánime, suele situarse entre los siglos VII y XI, constituye uno de los conjuntos más interesantes de la historia de la arquitectura prerrománica europea.
Para denominar esta arquitectura se ha discutido mucho sobre el calificativo o el determinante más conveniente. A este respecto, se sigue manteniendo una ya vieja polémica, "mozárabe" versus "de repoblación", que además de bizantina y esterilizante, ha impedido desarrollar otras líneas de investigación que en estos momentos 
podrían ser más esclarecedoras para el mejor conocimiento de esta realidad arquitectónica. Hace treinta años que señalé la importancia que tuvo para la arquitectura la restauración de viejas ciudades romanas y de sus edificios, no sólo por la reutilización de determinadas construcciones, sino porque, durante la restauración, se producía el aprendizaje de algunas técnicas constructivas a veces olvidadas $y$, especialmente, por el aprovechamiento de materiales ${ }^{1}$. Es este último aspecto el que pretendo desarrollar en este trabajo a partir del ejemplo que nos ofrece la construcción de San Miguel de Escalada, sin embargo, aunque sea muy brevemente, creo que sería muy instructivo replantearse algunos factores que son determinantes en el análisis del tema.

La presencia de algunos elementos "árabes" en esta arquitectura llevó a Gómez Moreno a considerar que estos se debían a la influencia de los mozárabes que habían emigrado a esta región. He insistido en multitud de ocasiones sobre este tema, señalando no sólo lo desacertado del término mozárabe tanto para el arte como para designar al grupo etnico/religioso, sino en la visión sesgada que da de la historia y cultura de esta época ${ }^{2}$. Es absolutamente incoherente calificar de mozárabe obras como Peñalba o Escalada y no hacerlo con San Isidoro de León, dado que uno de los arcos del muro occidental y los arcos del crucero

\footnotetext{
${ }^{1}$ Isidro G. BANGO TORVISO, "El neovisigotismo artístico de los siglos IX y X: La restauración de ciudades y templos", Ideas Estéticas, nº 148, Madrid, 1979, pp. 319 - 338. Volví a insistir sobre el tema en mi libro Arte Prerrománico Hispano. El arte en la España cristiana de los siglos VI al XI, Madrid, 2001, especialmente pp. $325-331$.

${ }^{2}$ Simplemente reseño a continuación mi último trabajo sobre el tema: “Un gravísimo error en la historiografía española, el empleo equivocado del término mozárabe", Simposio Internacional. El Legado de AlAndalus. El arte andalusí en los reinos de León y Castilla durante la Edad Media, coordimador Manuel Valdés Fernández, Valladolid, 2007, pp. 75 - 88.
}

no son menos "indiciarios" estilísticos que los de los citados edificios. Recientemente José María Mínguez ha analizado la posible actividad constructora de los mozárabes, señalando que sería más acorde con la realidad de la población considerarla propiamente árabe o beréber ${ }^{3}$. A esta referencia sobre el protagonismo de una población local islámica habría que añadir siervos y esclavos procedentes del reparto del botín de guerra que son entregados a las iglesias para trabajar. Pero si para el arte el concepto del llamado arte mozárabe resulta demasiado confuso y problemático, no lo es menos como denominador de una minoría religiosa. Ciertamente que la historiografía medieval hispana emplea el término de mozárabe con una gran soltura y prodigalidad, no lo es menos que este uso es extraordinariamente arbitrario. La misma palabra denomina a cualquiera de los cristianos que conservan su religión bajo el dominio del Islam, sea cual fuere la realidad de sus tradiciones y cultura. Así, mozárabe es un cristiano del siglo VIII como otro del siglo XI. Los mozárabes de los siglos VIII y IX parecían apegados a sus usos y costumbres preislámicos, sin que musulmanes o cristianos del Norte percibiesen nada que les permitiese calificarlos de arabizados. Ayam, nasara o dhimmíes son los nombres que emplean las fuentes islámicas para denominarlos. Cuando estos nasara se integran en territorio de hegemonía cristiana, lo hacen de pleno derecho en la sociedad, en ningún momento apreciamos algún elemento diferenciador. A partir del año mil, las fuentes cristianas utilizan un nuevo nombre para denominarlos: mozárabes. Esta palabra tiene su origen a partir de musta'rib, participio del verbo ista'riba, que significa "arabizarse". Justamente es en este momento

\footnotetext{
3 José M. Mínguez FernÁNDEZ, “Colonización y presencia mozárabe en el reino asturleonés. Un tema de debate", Simposio Internacional. El Legado de Al Andalus..., pp. $45-71$.
} 
cuando esta minoría religiosa acusa una marcada caracterización árabe, no sólo en su aspecto y su cultura material laica, sino incluso en los objetos y formas que sirven de soporte a su liturgia ${ }^{4}$. Los grupos de estos llamados mozárabes, generalmente bajo protección regia ${ }^{5}$, ya no se integran con el resto de los cristianos de su nueva patria, sino que forman mozarabías con regimenes muy particulares ${ }^{6}$. De todo esto resulta evidente que, tanto desde planteamientos políticos y culturales, es forzosamente necesario no utilizar la misma palabra para denominar dos grupos tan extraordinariamente diferenciados, máxime teniendo en cuenta que dicha palabra solo caracterizaría correctamente el segundo de los grupos.

Me parece que lo más significativo, para conocer la realidad de la arquitectura edificada durante estos siglos VIII al XI, es la importancia que el paisaje monumental existente entonces tuvo como modelo a imitar y como fondo a expoliar para reutilizar en la nueva edilicia de la época. No debemos olvidar que la presencia de construcciones del pasado en aquel momento era muy grande. Se trataba de obras muy sólidas construidas con materiales y técnicas que les permitían resistir el paso del

\footnotetext{
${ }^{4}$ Al estudiar las formas de la cultura de los cristianos bajo el patrocinio musulmán, se puede apreciar claramente como éstas no se islamizarán plenamente hasta el siglo XI (BANGO, Arte Prerrománico... , pp. 201 $-226)$.

${ }^{5}$ Resulta muy curiosos que esta minoría religiosa necesite de una protección especial del monarca al igual que la necesitaron los judíos (Isidro G. BANGO TORVISO, Remembering Sepharad. Jewish Culture in Medieval Spain, Washington Nacional Cathedral, Madrid, 2003, 139 y ss).

${ }^{6}$ Centrándose en el área leonesa, Gregoria CAVERO DOMÍNGUEZ ha estudiado con un agudo sentido crítico este fenómeno ("Los mozárabes leoneses y los espacio fronterizos", en La Península Ibérica en torno al año 1000. VII Congreso de Estudios Medievales, Fundación Sánchez Albornoz, 2001, p. 240 y ss).
}

tiempo ${ }^{7}$. Por otro lado, la falta de capacidad destructora de aquellas gentes, debida al descenso progresivo de la población y a los limitados recursos técnicos que disponían, sin olvidarnos del sentido práctico y utilitario que les movía a aprovechar todo lo existente, eran factores determinantes en la recuperación interesada de todo lo disponible. Pero, para poder comprender mejor este fenómeno de mantenimiento o recuperación del pasado, es necesario aproximarnos a la población de este territorio y su cultura material durante los siglos VIII al XI, y con ello nos introducimos de pleno con otro tema polémico: la despoblación/repoblación del Valle del Duero.

Para el interés de la materia edilicia que aquí nos interesa, la polémica se puede relativizar, pues los argumentos de unos y otros, tal como comentaremos a continuación, explican perfectamente las circunstancias en que surgieron los edificios más significativos de aquel momento. Ha sido Claudio Sánchez Albornoz, basándose en una tradición historiográfica fundada en noticias cronísticas y documentales, el que mejor ha definido el tema de la despoblación para después explicar como se había producido la repoblación. Después de señalar que el descenso del número de habitantes de la zona se venía gestando por diversas razones desde los siglos finales de la romanidad, acusándose en los últimos años de la monarquía goda, la invasión musulmana terminó por precipitar este proceso. A continuación, señala el texto de la Crónica albeldense en el que refiere como Alfonso I contribuyó a esta despoblación con sus campañas de castigo tomando ciudades y

\footnotetext{
${ }^{7}$ Sirva aquí de simple referencia las alusiones de las fuentes árabes la narrar las destrucciones de muros romanos como los de Mérida y León, que en realidad, como es bien conocido, no se trataba de otra cosa que una destrucción muy superficial que fundamentalmente se centraba en quemar las estructuras leñosas de las murallas. .
} 
conduciendo a los cristianos, como dice la Crónica de Alfonso III, a su patria: "xristianos autem secum ad patriam ducens". Todas estas circunstancias son las que propiciaron la creación de un desierto estratégico en el entorno del Duero que dio lugar a la existencia de "civitates eremas", "desertas" o en "solitudine relactas". Esta tesis de Sánchez Albornoz encontró cierta oposición, muy matizada, en Ramón Menéndez $\mathrm{Pidal}^{8}$, lo que le llevó a precisar que su consideración de despoblación lógicamente comportaba la persistencia de una población residual ${ }^{9}$.

En los últimos años, historiadores y arqueólogos han pretendido con sus estudios acabar con la tesis despobladora y por lo tanto relativizar la repobladora ${ }^{10}$. Mínguez, de una manera muy clarificadora, ha señalado las características de esta población que subsiste: "es un proceso que ya

-

8 "Dos problemas iniciales relativos a los romances hispánicos", en Enciclopedia Lingüística Hispánica, I, pp. XXIX y ss. Repoblación y tradición en la cuenca del Duero.

${ }^{9}$ El tema, que ha sido tratado en numerosos trabajos por Claudio SÁNCHEZ ALBORNOZ, tiene en su libro Despoblación y Repoblación del Valle del Duero, Buenos Aires, 1966, su obra de conjunto y síntesis más representativa.

${ }^{10}$ Los argumentos basados en razones económicas, sociales, toponímicas y arqueológicas son esgrimidos por los especialistas. Realizar aquí una síntesis historiográfica supera con creces mi intención y las posibilidades materiales de espacio. Los títulos que siguen a continuación son muy ilustrativos de esta postura: A. BARRIOS, “Toponomástica e historia. Notas sobre la despoblación en la zona meridional del Duero", España Medieval II. Estudios en memoria del profesor D. Salvador de Moxó, I, Madrid, 1982; J. A. GARCÍA DE CORTAZAR, "Del Cantábrico al Duero", en J. A. GARCÍA DE CORTAZAR et alii, Organización social del espacio en la España Medieval. La Corona de Castilla en los siglos VIII al XV, Barcelona, 1985, pp.; J. M ${ }^{a}$ MínGUEZ, "Innovación y pervivencia en la colonización del valle del Duero", en Despoblación y colonización del valle del Duero (siglos VIII - XX). IV Congreso de Estudios Medievales, León, 1995. Este último historiador ha realizado una breve pero magnífica síntesis en el trabajo ya citado, MíNGUEZ FERNÁNDEZ, “Colonización y presencia..." estaba en marcha en época visigoda"; "desarticulación del proceso productivo"; "desarticulación del sistema político administrativo centralizado que se manifiesta en una creciente autonomía y en el reforzamiento de los poderes locales"; "En el tejido social del campesinado ha penetrado ya el cristianismo lo suficiente como para que la religión y las prácticas de la liturgia constituyan elementos fundamentales de convivencia y de articulación social" ${ }^{\prime 1}$. Si los sistemas político y productivo están desarticulados, reduciéndose a un posible sistema autónomo y autárquico, huelga decir que las posibilidades comerciales no existen o están reducidas a su mínima expresión. En cuanto a que la práctica litúrgica del cristianismo constituye un sistema de vertebración social en sí misma no hay duda, pero habría que demostrarlo con los argumentos apropiados. Sin embargo esto no se confirma en la documentación conocida hasta el momento, todo lo contrario, los testimonios inmediatamente posteriores denuncian claramente este vacío de organización religiosa. ${ }^{12} \mathrm{Ni}$ la autoridad eclesiástica de los núcleos cristianos del Norte, ni la de la iglesia bajo hegemonía musulmana confirman

-

${ }^{11}$ Idem, pp. 47 y 49.

${ }^{12}$ Mari Carmen RodRÍGUEZ GONZÁLEZ, en su interesante síntesis sobre las restauraciones monásticas en el Bierzo, señala muy bien las dos fases de ocupación del territorio berciano desde finales de los siglos IX y $X$. Sin embargo lo que ocurre desde el fin visigodo, la desaparición de la vida monástica, hasta estas fases es una nebulosa basada en la carencia absoluta de información documentada, la paralización religiosa y la vuelta al paganismo por parte de una población mínima. En todo caso, como no podía ser de otra manera, "a partir de las fundaciones y restauraciones monásticas se intensifican las tareas colonizadoras que originan una trasformación del paisaje agrario primitivo" ("El papel de la aristocracia en las fundaciones y las restauraciones monásticas en el Bierzo del siglo $X^{\prime \prime}$, en El legado del santo, Xunta de Galica, 2007, pp. 48 63, espec. p. 60). No serán menos evidentes los cambios del paisaje agrario, que los que se produzcan en el paisaje monumental, producidos por la restauración y edificación ex novo 
su relación con posibles establecimientos eclesiásticos de la zona. Es imposible una práctica ritual del cristianismo sin la intervención episcopal. Podría pensarse en una cura pastoral ejercida por monasterios colonizadores, pero la existencia de éstos, como es bien conocido, corresponde ya a un período de repoblación del territorio. El mismo José $\mathrm{M}^{\mathrm{a}}$ Mínguez haciéndose eco de la opinión generalizada sobre este "período opaco a la escritura que se extiende desde los inicios del siglo VIII hasta el comienzo del siglo siguiente" nos dice que "la inexistencia de fuentes escritas no es indicativa de vacío de realidades sociales; de lo que estas lagunas documentales dan testimonio es de un vacío de instituciones capaces de generar documentación escrita" ${ }^{13}$. No creo que haya muchas diferencias entre la población residual a la que se refería Claudio Sánchez Albornoz en su tesis corregida más reciente y la población reducida y desarticulada a la que se refieren los que la niegan. Lo importante no es que no fuera capaz de crear una documentación escrita, que seguramente no lo era, sino que además, dada la precariedad de su existencia, no lo necesitaba. De la cultura material de estas gentes durante este período algo más podemos decir, pero sin duda no deja de ser un producto indicativo de la misma precariedad. $\mathrm{Al}$ analizar los sistemas defensivos tampoco se va más lejos, es necesario hablar de de una verdadera organización del territorio que se caracteriza por el fenómeno político/social más característico del momento: la repoblación ${ }^{14}$.

\footnotetext{
${ }^{13}$ Idem, p. 47.

${ }^{14}$ José Avelino GUTIÉRREZ GOZÁLEZ, en su análisis de este tipo de arquitectura militar, no duda en utilizar el nombre de "repoblación" para enmarcar el período que analiza y se entienda en el título de su trabajo: "Sistemas Defensivos y Repoblación en el Reino de León", en III Congreso de Arqueología Medieval Española. Actas, I. Ponencias, Oviedo, 1989, pp.169 - 191. Eso sí, le es necesario señalar que no se ha producido la despoblación de Sánchez Albornoz, aunque no sea capaz de
}

Nada similar a los edificios de finales del siglo IX o del $X$ de esta zona se erige en este período de vacio cultural, ni siquiera los considerados más humildes. Para que exista una arquitectura con ciertas pretensiones monumentales se requiere una sociedad articulada. Es la continuidad de este tipo de sociedad la que permitido que en Asturias las técnicas de la construcción no se hayan olvidado y que en un momento determinado se puedan realizar unos edificios de uso comunitario y de representación. Tal como he escrito en diversos trabajos, el Gijón romano debió ser la cantera de muchos materiales expoliados para edificar la nueva capital, Oviedo ${ }^{15}$. Se reutilizaba el material ornamental y de más especializada elaboración, tal como era habitual en los últimos siglos de la romanizad, pero las técnicas de construcción en general todavía se continuaban ejercitando. Será esta continuidad la que permitirá realizar los programas ideológicos diseñados por Alfonso II, el verdadero impulsor del neovisigotismo legitimador de la incipiente monarquía $^{16}$.

A lo largo del siglo IX, las tierras del Duero, habitadas por una población residual según Sánchez Albornoz o por una

señalar una población superior a la señalada por Minguez y otros, sino absolutamente en precario y desarticulada.

${ }^{15}$ Por no ampliar demasiado esta nota con los numerosos trabajos que he dedicado a este tema vid. una síntesis de los mismos en Isidro G. BANGO TORVISo, Arte Prerrománico...: "Una vieja ciudad romana como referente: Gijón, "ciudad marítima”, pp. 236 y ss.

${ }^{16}$ Parece increíble que todavía haya quien siga considerando que el principio de neovisigotización se debe a Alfonso III, ignorando o minimizando el papel de Alfonso II. Este es un tema fundamental para comprender el origen de la monarquía astur y su desarrollo ulterior. La historia del arte confirma absolutamente los planteamientos de las crónicas al referirse a este monarca, siendo la actuación de Alfonso III a este respecto una continuidad (Idem, "El neovisigotismo de unas formas artísticas al servicio de una ideología", pp. 229 y ss.). 
precaria y desarticulada población según sus críticos, empezará a conocer una doble colonización de tan vasto territorio infrahabitado: una es de carácter muy limitado llevada cabo por una familia o una pequeña comunidad monástica; la otra, de mayor entidad, pretende una reordenación del territorio creando ya los hitos suficientes para una administración civil y eclesiástica. La primera corresponde a familias e individuos en busca de tierras sin dueño en las que puedan alcanzar una oportunidad. Los monjes persiguen la soledad del idílico desierto o yermo para la práctica de su vida cenobítica. Muchos de ellos consideraban que aquellas ruinas de los viejos templos eran lugares de honda significación espiritual, pues eran tenidos por obra de los venerados padres del monacato hispanogodo ${ }^{17}$.

Desde el punto de vista arquitectónico, que es lo que nos interesa en este trabajo, ambas colonizaciones recurrieron a los mismos recursos técnicos e idéntico reempleo de materiales. Como he comentado anteriormente, hace muchos años que analice este tema a la luz de los textos, de los conocimientos histórico/artísticos, y arqueológicos. Es muy importante tener en cuenta que las noticias cronísticas, que evidentemente pueden estar manipuladas en función de determinados intereses ideológicos y políticos, están perfectamente avaladas por la documentación civil, que a este respecto no tiene sentido que responda a una falsificación ideológica interesada, y por el análisis constructivo de los edificios conservados. Veamos a continuación cuales

${ }^{17}$ He llamado la atención sobre la actividad restauradora de estos monjes, como en el caso de Genadio, que tomaban las antiguas construcciones para restaurarlas e imitarlas pues para ellos eran el ideal creado por san Fructuoso. fueron estas características del proceso edilicio de la época ${ }^{18}$.

En primer lugar nos llaman la atención las "ciudades desiertas" que citan las crónicas y documentos de la época. Es cierto que estas ciudades durante el Bajo Imperio habían visto disminuir su población por cuestiones de precariedad económica, productiva e infecciosa (inguinalis plaga), agravándose el fenómeno aún más por la acción de bandidos e invasores. Tras las invasiones bárbaras, hubo un sensible repunte del hábitat, sin embargo, ya desde los primeros tiempos de hegemonía islámica, la población iría en progresivo descenso. Los jefes cristianos de la resistencia norteña se ocuparon muy pronto de crear un espacio de "tierra quemada" en esta zona. El Albeldense $(\mathrm{XV}, 3)$ nos informa que Alfonso I (739 - 757) realizó algaradas quemando ciudades en los llamados Campos Góticos y reconduciendo a los cristianos que allí había hacia su pequeño reino:

"Hurbes quoque Legionem atque Asturicam ab inimicis possessas uictor inuasit. Campos quem dicunt Gothicos usque ad flumen Dorium eremauit et Xpianorum regnum exten$d_{i t}{ }^{\prime 19}$

La Crónica de Alfonso III (Rotensis, 13) es mucho más precisa al describir los detalles de esta campaña de Alfonso I. Nos habla de una campaña guerrera y nos explicita el nombre de las ciudades yermadas:

"Adefonsus... Qui cum fratre Froilane sepius exercitu mobens multas ciuitates bellando cepit. Id est Lucum, Tudem, Portuga-

-

${ }^{18}$ El resumen que ofrecemos a continuación tiene un mayor desarrollo documental en las obras que recojo en la nota $n^{0} 1$. Las citas que se reproducen a continuación, salvo indicación de lo contrario, pueden completarse con su correspondiente aparato crítico en estos trabajos.

${ }^{19}$ Las citas a las crónicas asturianas, si no hay indicación de lo contrario, se harán por la edición de Juan Gil (Juan GIL FERNÁNDEZ, José Luís MORALEJO y Juan L. RUÍZ DE LA PEÑA, Crónicas asturianas, Oviedo, 1985), p. 173. 
lem, Anegiam, Bracaram metropolitanam, Uiseo, Flavias, Letesma, Salamantica, Numantia qui nunc uocitatur Zamora, Abela, Astorica, Legionem, Septenmanca, Saldania, Amaia, Secobia, Oxoma, Septempuplica, Arganza, Clunia, Mabe, Auca, Miranda, Reuendeca, Carbonarica, Abeica, Cinasaria, et Alesanzo seu castris cum uillis et uinculis suis, omnes quoque Arabe gladio interficiens, Xpianos autem secum ad patriam ducens $^{\prime \prime 20}$

A partir de este momento las referencias cronísticas y documentales sobre estas ciudades insisten una y otra vez en calificarles con los siguientes términos: "urbes desertas", "civitates eremas", "civitate ex ruina desolata", "in solitudine relacta". Es sobre estas ciudades sobre las que tiene lugar la acción repobladora de los monarcas. La Crónica de Sampiro (14) refiere la actuación de Alfonso III a este respecto en los siguientes términos y en relación con las siguientes ciudades:

"-Alfonso III- Ac trienio peracto, sub era DCCCCXIII, urbes desertas ab antiquibus, populari rex iussit. Hec sunt Cemora, Septimancas, et Donnas uel omnes Campi Gotorum; Taurum nanque ad populandum dedit filio suo Garseano" 21

La misma crónica atribuye a Ramiro II la repoblación de "ciuitates desertas" de Ledesma, Ribas, Baños, Alfandega, Peña y otros muchos castillos (plurima castella). ${ }^{22}$ Hacia el occidente, la actuación repobladora de los condes castellanos era muy similar, según nos dicen los Anales Castellanos con referencia al año 912: el conde Gozalo Fernández pobló Clunia, San Esteban de Gormaz, Aza; Gonzalo Tellez, la antiquísi-

${ }^{20}$ Crónicas asturianas, p. 130 - 132. En los mismos términos se expresa la edición Ad Sebastianum (Idem, $\mathrm{p}$ 131 - 133).

${ }^{21}$ Fray Justo PÉREZ DE URBEL, Sampiro. Su crónica y la monarquía leonesa en el siglo X, Madrid, 1952, p. 305.

${ }^{22}$ Crónica de Sampiro, 23, p. 327. ma Uxama; y Nuño Nuñez repobló la antigua Rauda ${ }^{23}$.

¿En qué consistió la restauración de estas ciudades? La organización y limpieza de la parte principal de la antigua red viaria era una de las tareas iniciales. La escasez de población no permitía reaprovechar la totalidad del caserío que todavía permaneciese en pie. Muchas áreas urbanas aparecían arruinadas y en muchos casos conocemos como se convoca a las gentes que vivían en su entorno para que habiten en el interior, donde se establecen apriscos de ganado e incluso huertas. Pero la gran obra comunitaria será el muro que protege la ciudad. Aunque en muchas ocasiones las noticias históricas nos informan de cómo el ejército musulmán destruye sus muros, es evidente que su acción destructora no pasó de destruir las puertas y las infraestructuras leñosas de las partes superiores, tal como ya hemos comentado anteriormente. Destruir unos muros romanos, con su enorme potencia constructiva, no era labor fácil y requería tantos hombres y tal cantidad de tiempo que no parece creíble que un ejército en marcha, que ocupaba unos pocos días una ciudad, lograse hacer grandes destrozos del encintado mural. Lo que sabemos de las murallas de Mérida y de León son buena prueba de todo esto. Lo que parece más lógico es que quemasen las puertas y corredores, cadalsos y estructuras aéreas en general. Es en este sentido como se entienden las palabras del Albeldense cuando se refiere a la actuación repobladora en estas ciudades. "...portas in altitudinem posuit" o

\footnotetext{
${ }^{23}$ La misma Crónica de Sampiro amplia la relación de ciudades repobladas por los condes durante este reinado:"Tunc temporis populauit Rodericus comes Amaiam, et predauit. Asturias in partes sancte Iuliane. Populauit Didacus comes Burgis, et Ouirnam per iussionem regis. Populauerunt autem comes Nunnius Monnioni Raudam, et Gundisaluo Fernandiz Azcam, Cluniam et Sanctus Stephanum. Populauit Fernando Gunsaluit ciuitatem que dicitur Septempublica cum Dei auxilio" (pp. 327 y 328).
} 
"circumquaque munientibus, altis circuire fecit".

Si abordamos el tema de los edificios, prácticamente el único con pretensiones monumentales es el templo y en algunos casos ampliado al monasterio. De un paisaje monumental en el que subsistían un número considerable de iglesias abandonadas, la documentación de los siglos IX al XI es un testimonio indiscutible. Después la referencia a este tipo de edificios abandonados será insignificante, incluso absolutamente negativo. Aunque, por las circunstancias de la documentación, sólo se suele citar un solo edificio abandonado en un diploma, no faltan las referencias a varios, inclusive podemos ver que a veces se habla de todo un territorio con sus iglesias abandonadas: En este último sentido resulta muy esclarecedor el diploma que recoge la donación al monasterio de San Martín de Flabio, por parte del abad Paulo, el presbítero Juan y el clérigo Nuño, de las siguientes iglesias que habían conseguido por presura: Santa María de Govia, San Juan de Quenquences, Santa María de Rusión, San Martín de Vuillalumnos, Santa Agatea de Manata y San Román de Valcavata. El abad Abito, al fundar el monasterio de Tobiellas en el año 811, hizo donación de siete iglesias que había apresado: "Sancti Michael in rivo Tiron, prissi Sancte Marie in Lara... prissi ibi media ecclesia Sanctorum Cosmas et Damián... et prissi media ecclesia Sancti Mamitis et media de Comunione".

De estos numerosísimos templos abandonados se nos dan ciertos detalles sobre estas circunstancias: que eran "antiquas"; que estaban en un "locum antiquum", o eran "ex more antiquo"; "ex fundata ab antiquis relictam"; "ecclesias antiquo fundamine consitas". Su situación en despoblado es muy evidente: "eclesia in solitudine", "descalido", "ecclesiam desertam", "monasterium desertum"... Generalmente la referencia al tiempo de abandono se limita a decirnos que es "de antiguo": "de antiquo"; "multis temporibus maebat desertam". Pero tampoco faltan ciertas precisiones cronológicas. En el año 906 el presbítero Gratón donó al diácono Gonzalo, hijo de Alfonso III, una iglesia en Monzón que había sido destruida por los musulmanes: "quod fuit dirupta a paganis". Incluso hay quien llega a precisar el tiempo del abandono. En el año 872, el diácono Odoyno recibe dos iglesias que estaban abandonadas desde hacia más de dos siglos:

“...ex quibus unam villam dedit congermano suo Odoyno diacono qui est in ripa Limie cum ecclesis de antiquitis annis hedificatas dictas et vocatas Sancte Marie semper Virginia et martiris, que iacebant in exqualido de ducentis annis aut plus"

No basta indicar aquí que las cifras de edificios abandonados $\mathrm{y}$ reconstruidos de esta época carecen de parangón en ningún otro momento, tal como ya hemos indicado, sino que además los grandes edificios catedralicios o monasteriales, si conocemos de manera indiscutible su origen, se construyen sobre unas estructuras abandonadas.

Hay tres factores determinantes para aprovechar las viejas fábricas monumentales del pasado: el prestigio de lo hispanogodo como referente; la utilidad funcional de las estructuras templarias; y la economía de medios dada la precariedad económica del momento.

Bajo el reinado de Alfonso II (791 842) se había consolidado un fuerte sentimiento de neovisigotismo, entendido éste como un referente legitimador para la monarquía y sus instituciones ${ }^{24}$, mientras que

\footnotetext{
${ }^{24}$ Desde la indicación del texto del Albeldense sobre el neovisigotismo de Alfonso II todos los monarcas siguientes defenderán durante un tiempo este principio legitimador del pasado. Como he indicado en numerosas ocasiones no se aprovechaban las viejas construcciones del Duero sólo por un sentido utilita-
} 
en lo cultural en su sentido más amplio el referente sería lo que llama la historiografía actual cultura hispanovisigoda. Así estas imponentes fábricas monumentales, aunque arruinadas, constituían en sí mismas todo un ideal a imitar. Para los monjes repobladores, fervientes seguidores de Fructuoso y Valerio, la búsqueda y restauración de los monasterios fundados por estos santos de la España visigodo se convirtió en su más profundo anhelo vital. Se buscan estos monasterios y todas aquellas ruinas que se puedan relacionar con los padres del pasado para convertirlos en centro de su veneración. Con este criterio debemos entender la actividad restauradora llevada a cabo por san Genadio y sus monjes. De esta manera, se podría decir, salvando las distancias, que las viejas fundaciones hispanogodas se convertían en un clásico para los repobladores. Así el viejo imaginario necesariamente tenía que seguir siendo el mismo y los antiguos edificios eran piedras veneradas como reliquias del pasado.

Desde el punto de vista funcional los edificios conservados no ofrecían ninguna dificultad para su reutilización. La topografía sagrada que presentaban era el mismo escenario que se necesitaba para la práctica del ritual, pues la liturgia no se había modificado en absoluto. Tampoco había necesidad de cambio alguno para las dependencias monásticas, pues las reglas y usos monasteriales seguían siendo los mismos. Tanto los cristianos del Norte como

rio, sino que en muchas ocasiones había toda una carga de ideología legitimadora y de continuidad de la dinastía. En este sentido los mármoles trasportados por Alfonso III a Compostela han sido interpretados también por Fernando López Alsina (Isidro G. BANGO TORVISO, "El locus sanctus de Santiago de Compostela. Una nueva interpretación del escenario arquitectónico del santuario", en El camí de Sant Jaume i Catalunya. Actes del Congrés Internacional celebrat a Barcelona, Cervera $i$ Lleida, els dies 16, 17 i 18 d'octubre de 2003, Publicacions de 1'Abadia de Montserrat, 2007, pp. 209 210). los sureños practicaban la misma liturgia para la que habían sido concebidos estos viejos templos abandonados. A este respecto resulta muy curioso, por excepcional, el caso de la nueva catedral leonesa. La expansión del reino astur hacia el sur con Ordoño I (850 - 886) comportaba una organización del territorio tanto en lo civil como en lo eclesiástico. Para este último fin lo principal era fundar las sedes episcopales. En la ciudad de León no se conservaba ni un solo templo que pudiese alojar la catedral. Por esta razón se establecería en un monasterio en las afueras de León, el de San Pedro y San Pablo ${ }^{25}$. Habrá que esperar al siglo X para que Ordoño II (914 - 924) disponga el traslado al interior de la ciudad. Por entonces la urbe se había reorganizado en su tejido urbano y las viejas construcciones romanas subsistentes aprovechadas para las necesidades de los nuevos habitantes. El palacio real se había erigido en las dependencias de un fanum de un conjunto termal, el monarca dispuso que tres pabellones se utilizasen como catedral: dos pabellones como templo propiamente dicho, mientras que el tercero, constituyendo un edificio independiente tal como indicaba la normativa canónica, era destinado a baptisterio ${ }^{26}$. Este edificio con diferentes añadidos estaría en vigor hasta la gran re-

\footnotetext{
${ }^{25}$ Durante estos siglos, la restauración de las sedes episcopales generalmente comportaba una primera fase en la que el obispo y su catedral eran alojados, provisionalmente, en un monasterio. A veces la provisionalidad duraba muchos años (Isidro G. BANGO TORVISO, "Catedral de León. Desde la instauración de la diócesis hasta la magna obra de Manrique de Lara", en La Catedral de León en la Edad Media, edit. Joaquín Yarza Luaces, $M^{\mathbf{a}}$ Victoria Herráez Ortega y Gerardo Boto, Universidad de León, 2004, pp. 45 - 57). En la más antigua tradición eclesial ha existido la figura del abad/obispo. Para este período y área geográfica ha sido estudiada por Dolores MARIÑO VEIRAS ("Obispos en la Iglesia Regio-Aristocrática o del Regnum Leonés: Aproximación a alguna de sus figuras, funciones y a la transmisión de la dignidad episcopal (910 - 975), en La Catedral de León en la Edad Media, pp. 459 - 470).

${ }^{26}$ Idem, pp. $47-49$.
} 
novación, que ya incluiría seguramente obra románica, llevada a cabo por el obispo Pelayo en $1063^{27}$.

Por último, la tercera razón para la reutilización de todos estos antiguos edificios radicaba en la realidad de la economía y de los recursos de mano de obra. Si no se podía aprovechar un viejo edificio o había que ampliarlo, las ruinas conservadas tenían una riqueza tal de materiales que no había más que tomarlos. Incluso habría dificultades para realizar fustes o capiteles de la calidad material y factura de los existentes.

Por último analicemos brevemente en que consistía la actuación de los repobladores en la reutilización de estos edificios. El proceso lo marca de una manera muy precisa Alfonso III al conceder una serie de privilegios al abad Recesvinto de Sahagún con el fin de que proceda a "restaurar, ampliar y dotar" su destruida basílica por los ismaelitas:

"Ego Adefonsus gratia Dei rex cum cónyuge Scemena qui studuimus hanc baselicam restaurare, ampliare et ditare quam a hismaelita oste dinoscitur fuise diruta ${ }^{\prime 28}$.

Aquí quedan perfectamente claros los pasos a seguir: Primero se restaura (restaure). Segundo, cuando fuere necesario, se amplia (ampliare), pues lógicamente la fundación se hará cada vez más grande. Tercero se dota (ditare). Este término "ditare" tiene un sentido amplio que denomina la dotación general de un templo, tanto de bienes muebles como inmuebles; sin embargo, en muchas ocasiones significa con absoluta precisión los ornamentos litúrgicos que constituyen el tesoro sagrado.

${ }^{27}$ Idem pp. $51-53$.

${ }^{28} 30$ de noviembre de 905 (José María MíNGUEZ FERNÁNDEZ, Colección Diplomática del Monasterio de Sahagún-Siglos IX y X-, 1977, doc. ํo 8, p. 30).
¿En qué consiste la restauración de un templo del pasado? En 1 mayoría de los casos no se hace mención de ello, dada la solidez de estas construcciones es muy posible que una limpieza y la reposición de la carpintería de puertas y ventanas así como el mobiliario ritual fueran suficientes. En algunos edificios se nos informa que los techos se habían hundido, tal como consta en la donación de Alfonso $\mathrm{V}$ a Sarracino Arias:"iacebat erema sine tectos". El obispo Diego de Valpuesta, en el 940, al referirse a la actuación restauradora en las iglesias de Merosa, nos indica que consistió en "cubrir las iglesias". Aunque no contásemos con este tipo de referencia, es bien sabido que la causa de ruina de estas construcciones es el fallo del tejado con su correspondiente hundimiento. Otras veces se alude al derrumbe de las paredes, tal como cita Alfonso III al referirse a las casas e iglesias de la villa de Alesce, cuyas paredes estaban destruidas: "cum parietibus destructis" 29 .

Sobre los materiales reaprovechados contamos con dos tipos de información: documentales y arqueológicos. La reparación llevada a cabo por el obispo Diego de Valpuesta en sus fundaciones de Merosa nos aclara como el expolio de viejas iglesias arruinadas servía para tal fin:

“...Llevamos madera de cuatro casas y una troje y las tejas de tres iglesias de Valpuesta, componiendo con la dicha madera las casas y las iglesias de Villa Merosa"

De la precariedad de medios de la época, incluso para algo tan simple como las cubiertas, nos suministra un ejemplo excepcional lo sucedido en el poblado de Diego Alvaro, siglos IX o X, donde se utilizaron pizarras epigrafiadas visigodas para

${ }^{29}$ Antonio López FERREIRO, Historia de la Santa A. M. Iglesia de Santiago de Compostela, t. II, Santiago, 1899, apéndice $n^{\circ} X I$, p. 23. 
la cubrición ${ }^{30}$. Pero lo que el estudio de los edificios conservados pone mejor de relieve y la documentación atestigua de manera paradigmática es el empleo de viejas columnas y relieves. Alfonso III para la nueva construcción del santuario compostelano hizo traer columnas, columnillas, capiteles, basas y cimacios desde Eabeca, en territorio "portu-calense" ${ }^{\prime 31}$.

El reaprovechamiento de materiales de edificios antiguos siempre ha sido una constante en el arte romano, especialmente desde el siglo IV. El arte hispanovisigodo cuenta con ejemplos muy elocuentes. Podemos observar en los intercolumnios que conforman las tres naves de San Juan de Baños, posiblemente erigida por Recesvinto en 652 ó 661, sus columnas han sido re-

-

${ }^{30}$ A. GUTIERREZ PALACIOS, Miscelánea arqueológica de Diego Alvaro, Avila, 1966, p. 81 - 92.

31 "Nos quidem inspiratione diuina adiuti cum subdditis familia nostra adduximus in sanctus locum ex Hispania inter agmina maurorum, quae eiecimus de ciyuitate Eabecae patras marmoreas quas aui nostri tribus per ponyum transvexerunt, et ex eis pulcras domos aedificaerunt, quae ab inimicis destructae manebant... Columnas sex cum basibus totidem posuimus, ubi abbobuta tribunales est constructa. Vel alias columnas sculptas, supra quas porticus inminet. De oppido portucalense ratibus deportatas adduximus cuadros et calcem unde sunt aedificatae columnae decem et VIII, cum aliis columnellis marmoreis simili modo nauigio". Sobre la edición de este documento y la utilización de estos materiales expoliados en la construcción del templo compostelano de Alfonso III véase mi ponencia, I. G. BANGO TORVISO “El locus sanctus....”, pp. 191 - 220. Es excelente el estudio del texto, desde el punto de vista de la edición crítica, el trabajo de J. M. DÍAZ De Bustamante y J. E. López PereirA, "El acta de consagración de la catedral de Santiago: Edición y estudio crítico", en Compostellanum, 35 (1990), pp. 377 340. Sobre este tema ha tratado Claudio SÁNCHEZ AlBORNOZ, "Mármoles romanos en la iglesia Alfonsí de Compostela" en Cuadernos de Historia de España, 63 64 (1980), pp. 347 - 351. Se ha querido identificar la ciudad de Eabeca citada en el documento con Coria, siendo los materiales reaprovechados con motivo de la repoblación llevada a cabo en este lugar por Alfonso III (J. E. LÓPEZ PEREIRA, “Mármoles romanos de la iglesia de Santiago de Alfonso III: determinación de su procedencia", en Madrider Mitteilungen , 34 ( 1993), pp. $275-281)$. aprovechadas de una obra anterior (Lám. 1). Los constructores hispanos de la primera fase de la mezquita de Córdoba reaprovecharon fustes y capiteles de todo tipo sin consideración alguna por mantener una mínima regularidad aunque sólo fuera en tamaño (Lám. 2). El tercer ejemplo es de cronología más problemática, pero en todo caso, y teniendo en cuenta la datación más lata que se le pueda dar, resulta mucho más significativo para el argumento que aquí nos interesa. Me refiero a la antigua mezquita toledana convertida después en iglesia del Salvador. Su arquerío (Lám. 3), de columnas reaprovechadas con capiteles tardorromanos ${ }^{32}$, no difiere de la tradición de Baños o Córdoba y del que veremos a continuación de las iglesias de San Cebrián de Mazote o de San Miguel de Escalada. Recientemente se han realizado importantes actividades arqueológicas en este monumento toledano, pero, aunque no conozco el informe de las mismas por escrito, no parece que modifique sustancialmente su interpretación y cronología: de este edificio consta la reedificación de una nave en el siglo XI, aunque el conjunto de la mezquita debe ser obra de los siglos IX y $X^{33}$. La interpretación que realizó Gómez Moreno sobre la iglesia de Mazote sigue siendo válida para la mayoría de los estudiosos de

\footnotetext{
${ }^{32}$ La utilización del término tardorromano aquí pretende ser conscientemente ambiguo: sin duda hay restos que podrían ser calificados de hispanogodos, sin embargo prefiero llamarlos tardorromanos pues en realidad se trata de unas formas y unas técnicas que convienen mejor con tardorromano incluyendo bajo esta nomenclatura, aunque sea de forma epigonal, la correspondiente a los siglos VI y VII.

${ }^{33}$ Clara Delgado VAlero, Toledo Islámico: ciudad, arte e historia, Toledo, 1987, pp. 274 - 283. Para Basilio PAVÓN MALDONADO, siguiendo a Gómez Moreno, se trata de columnas romanas y visigodas aprovechadas, aparte de interesantes pilastras ricamente labradas de este último estilo" (Arte toledano: islámico y mudéjar, Madrid, 1973, p. 55).
} 
este monumento ${ }^{34}$. El insigne historiador granadino nos informa con gran admiración: "Los capiteles forman colección notabilísima en esta iglesia; llegaría su número a cuarenta de los que permanecen cuarenta.... Dominando gran variedad, aunque dentro del tipo corintio siempre" (Lám. 4). Impresionado por su hermosura y calidad no duda en proponer una clasificación cuando menos extrañísima: "Su belleza, perfección técnica y refinamientos ponen estos capiteles a la cabeza de todos sus similares, españoles y franceses, correspondientes a la Edad Media remota, pudiéndose asegurar de ellos una cosa, y es su abolengo oriental, siriaco acaso, más bien que bizantino, y con tal pureza de estilo y tal variedad que han de creerse obra de artistas $\operatorname{asiáticos}^{\prime 35}$. No quiero entrar en la discusión de los términos de esta definición, fruto de un concepto historiográfico muy característico de finales del siglo XIX, sin embargo si creo pertinente afirmar algo que me parece fuera de toda discusión: De todos estos capiteles tan sólo dos parejas, y sinceramente no lo creo, han sido realizados para el edificio; todos han sido reaprovechados de obras anteriores, expolios de edificios arruinados. Ni igualdad de tamaños, ni similitudes tipológicas, ni adecuación con fustes y cimacios, ni siquiera de cantera para los materiales. El problema no está en reconocer que son reaprovechados que, desde mi punto de vista es algo indiscutible, sino en fijar su cronología. Si estamos ante un material reaprovechado, lógicamente deberemos deducir que para el

\footnotetext{
${ }^{34}$ Se suele datar este templo a partir de la documentación de San Martín de Castañeda, donde consta que su abad Martín con sus monjes habitaron Mazote en el año 916 (M. GóMEZ MORENO, Iglesias Mozárabes, Madrid, 1919, pp. 172 185). Para su contextualización en un prototipo templario bipolarizado de origen hispanogodo véase I. G. BANGo TORVISO, Arte Prerrománico..., pp. 347 - 348).

${ }^{35}$ M. GÓMEZ MORENO, Iglesias mozárabes.., pp.182 183.
}

siglo $\mathrm{X}$ pertenecían a una construcción o construcciones que entonces estaban arruinadas. A esto deberíamos añadir que un edificio del siglo VII o del VIII, y seguramente incluso de siglos anteriores, también podía haber sido construido con material de acarreo tal como ya hemos podido comprobar. Todavía hay otro problema más añadido, carecemos de seriaciones sistemáticas, fidedignas y completas de capiteles de la edilicia hispana de los siglos IV al VII ${ }^{36}$.

Pero, si el soporte nada nos ayuda para el conocimiento de la cronología, menos nos aporta el análisis de los arcos de herradura, pese a que a este respecto algunos tratadistas han abusado demasiado de lo que consideran unas reglas normativas del arco de herradura. Este tipo de arco sólo tiene una característica constante e indiscutible: el peralte del arco está en función del sentido tectónico o estético que tenga. En un mismo edificio, como es lógico por lo que acabamos de decir, podemos encontrarnos diferentes tipos de peralte y de caracterización de organización de la rosca y el dovelaje. Sólo en obras de gran calidad del ámbito andalusí se terminará por codificar un cierto modulo y código formal. En todo caso en la segunda parte de este artículo volveremos a este tema.

En el marco de todos estos planteamientos generales me propongo realizar una relectura de un edificio como San Miguel de Escalada tan importante para esta área geográfica y la cronología que aquí nos interesa. Desde mi punto de vista, la documentación histórica indica aspectos y circunstancias diferentes a los que habitual-

\footnotetext{
${ }^{36}$ Sería injusto negar el enorme esfuerzo por realizar este estudio que, desde los pioneros trabajos de Schlunk, se ha venido haciendo hasta nuestros días. La visión más reciente que conozco a este respecto es la de Javier Ángel DOMINGo MANGaÑA, Capiteles Tardorromanos y Altomedievalesde Hispania (ss. IV - VIII $d C$ ), Tesis doctoral leída en a Universitat Rovira y Virgili, 2006.
} 
mente se han argumentado. Por otra parte, estos datos documentados obligan a una reinterpretación del proceso constructivo y de la verdadera cronología del material reaprovechado. Todo ello creo que debería reconducir a un replanteamiento general de la arquitectura de esta época.

\section{EL PROCESO CONSTRUCTIVO DE SAN MIGUEL SEGÚN LOS DATOS DOCUMENTADOS}

De todos los templos conservados de esta época, el de San Miguel de Escalada reúne una serie de testimonios históricos y un conjunto arquitectónico que nos permiten realizar una aproximación al proceso constructivo del mismo. Cierto que todo ello es de problemática interpretación y a veces de información escasa y demasiado confusa; sin embargo ningún otro edificio coetáneo dispone de tal nivel de información. Considero que es, a partir de un edificio como éste, como se puede iniciar un replanteamiento de la historia de la arquitectura del período que va desde el tardohispanogodo hasta las primeras manifestaciones del estilo románico. Aunque no hemos avanzado mucho desde el estudio de Gómez Moreno, no sería justo no reconocer las meritorias aportaciones realizadas desde entonces ${ }^{37}$.

${ }^{37}$ El primer estudio "moderno" del edificio y su historia se debe a GÓMEZ MORENO cuando en 1906 se encargó de realizar la catalogación de la provincia de León., aunque no se publicaría hasta casi veinte años después: Catálogo Monumental de la Provincia de León, 2 vols., Madrid, 1925, pp. 100 - 109. Poco después de su viaje por tierras leonesas editaría una escueta visión de la arquitectura mozárabe: "De arqueología mozárabe", en Boletín de la Sociedad Española de Excursiones, T. 21, 1913, pp. 89 y ss. Pero su obra definitiva aparecerá en libro publicado en 1919, M. GómEZ MORENO, Iglesias Mozárabes, p. 141 - 162. La riquísima información epigráfica de Escalada será estudiada por V. GARCíA LOBO (Las inscripciones de San Miguel de Escalada. Estudio crítico, Barcelona, 1982) corrigiendo malas lecturas y precisando algunos hitos importantes de la historia
1.1. La información del epígrafe del abad Alfonso

La célebre inscripción de Escalada en la que se fundamenta la historia inicial del monasterio, hoy en paradero desconocido, se encontraba sobre una puerta situada en

del monumento. Con las excavaciones llevadas a cabo por Hortensia LARRÉN IZQUIERDO conocimos el subsuelo de la iglesia clarificando algunos aspectos de la construcción, pero en general no aparecieron testimonios que fueran definitivos para la historia del monumento. En todo caso, el trabajo de Larrén ha puesto de manifiesto, a mi parecer, que carecemos de testimonios de estadios intermedios entre lo que se consideraría una obra tardorromana de uso civil y el edificio que podemos contemplar en la actualidad. Los resultados de la excavación han sido publicados en tres artículos: "Excavaciones arqueológicas de San Miguel de Escalada (León)", en Actas del I Congreso Nacional de Arqueología Medieval Española, t. II (Visigodo), Zaragoza, 1986, pp. 103 - 123; "Aspectos visigodos de San Miguel de Escalada (León)", en Los Visigodos. Historia y Civilización. Actas de la Semana Internacional de Estudios Visigóticos (Madrid -Toledo - Alcalá de Henares) publicadas en Antigüedad y Cristianismo, III, Murcia, 1985, pp. 501 513; "San Miguel de Escalada: Trabajos arqueológicos (1983 - 1987)", en Numantia no 3, 1990, pp. 217 - 238. En los últimos años se han realizado nuevas prospecciones arqueológicas cuyos resultados desconozco. La tesis doctoral de Domínguez Perela sobre los capiteles hispanos altomedievales, durísimamente criticada por los defensores de arqueología más ultraconservadora, fue una llamada de atención sobre los grandes defectos de los métodos de estudio de estas obras. La parte publicada en lo que se refiere a nuestro templo es paradigmática sobre este tema (Enrique DOMÍNGUEZ PERELA, "Los capiteles del pórtico de Escalada, entre la tradición clásica y la bizantina, lo islámico y la creación local", en $V$ Congrés Espanyol d'Historia de l'Art, Vol. I. Barcelona; 29 d'octubre al 3 de novembre de 1984, Barcelona, 1986, pp. 65 -75). Artemio MARTínEZ TEJERA ha realizado un estudio sistemático del edificio y de la historiografía que el mismo ha generado (El templo del monasterium de San Miguel de Escalada, Madrid, 2005, pp. 61) es un buen trabajo que ha aclarado aspectos importantes del monumento y que serán de gran utilidad para todos aquellos que continúen en su estudio. El aparato crítico utilizado es tan completo que lo recomiendo para todos aquellos estudios que para mi trabajo no he considerado oportuno relacionar en las páginas siguientes. Muy meritorio es el esfuerzo realizado por Javier Ángel DOMINGO MANGAÑA para sistematizar los capiteles de Escalada (Capiteles Tardorromanos y Altomedievalesde..., pp. 333 - 340. 
el exterior de la iglesia, en una de las dependencias monasteriales de San Miguel ${ }^{38}$. Reproducimos aquí la trascripción y lectura que ha trasmitido a la comunidad científica posterior M. Risco:

Hic locus antiquitus Michaelis archangeli honore dicatus, brevi opere instructus, post ruinis abolitus, diu mansit dirutus, donec Adefonsus abba cum sociis adveniens ad Corduvensi patria edis ruinam erexit sub valente sereno Adefonso Principe. Monachorum numero crescente, demum hoc templum decorum miro opere a fundamine exundique amplificatum erigitur. Non jussu imperial, $i$ vel oppresione vulgo,, sed Abbatís Adefonsi, $\mathcal{E}$ fratrum instante vigilantia duodenis mensibus peracta sunt haec opera, Garsea sceptra Regni peragens Mumadomna cum Regina.

\section{ERA DCCCCC LI}

Sacratumque templum ab Episcopum Jennadium XII. Kal. Decembrium ${ }^{39}$

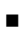

${ }^{38}$ Aunque DOMINGO MANGAÑA (Capiteles...p. 333) siguiendo (D. ANEDDA, "La desaparecida inscripción de consagración de la iglesia de San Miguel de Escalada: un acercamiento prudente" en Sacralidad y Arqueología. Homenaje al Prof. Thilo Ulbert al cumplir 65 años. Antigüedad y Cristianismo, XXI, 2004, pp. 375-385) afirme que "no podemos tener la certeza absoluta de la existencia de esta inscripción pues son numerosos los textos y documentos que no hacen ninguna mención a ella y quizás Risco nunca la vio directamente sino que simplemente recogió una tradición local", no parece que se pueda tener grandes dudas sobre ella dado su seguimiento hasta fechas relativamente recientes. Según el prior Menéndez Valdés "este rótulo se encontraba en una piedra de mármol de jaspe que cubre el arco y la puerta que lleva a Trianos en la segunda puerta como si entra en dicho claustro" (MARTínEZ TEJERA El templo..., p. 19. En Martínez Tejera podemos seguir las peripecias de esta inscripción hasta 1855, año que la volvió a publicar José María Quadrado, el último de sus publicistas que la pudo ver.

${ }^{39}$ M. RISCO, España Sagrada, XXV, Madrid, 1786, p. 311. A partir del texto de Risco se han sucedido lecturas e interpretaciones que superan la veintena. Por su carácter muy reiterativo o demasiado incongruentes prescindimos de la mayoría, señalando a continuación aquellas que considero importantes: $R$. Alvarez De La BraÑa, "San Miguel de Escalada", en RABM 4(1874), P. 377, N. 4; F. FITA, "San Miguel de Escalada. Inscripciones y documentos", en BRAH 31
Lógicamente una lectura como esta contiene todos los problemas inherentes a su época, deudora de las reglas histórico documentales del siglo XVIII. Los expertos discuten sobre letras concretas o planteamientos de morfosintáxis, todo ello propio de un "criterio normativista y normativizador" de la lengua latina ${ }^{40}$. Pese a todos estos problemas, la mayoría de los especialistas parecen estar de acuerdo que ningún error de fondo se puede atribuir al contenido mismo.

Este epígrafe forma parte del grupo que los estudiosos suelen denominar Monumenta aedificationis ${ }^{41}$. Con motivo de un acto solemne (dedicación, consagración, restauración, etc) se recogen una serie de hitos en la historia del edificio o la institución a la que éste pertenece. No es, como alguna vez se ha dicho, un acta de consagración monumentalizada, aunque su realización si se haya debido a la celebración de la consagración que se cita en la inscripción.

En los apartados siguientes haremos un breve análisis crítico de los hitos históricos que recoge la inscripción, intentando aclarar algunos aspectos del exacto significado de algunos términos, así como aclarar, en la medida de lo posible, ciertas fases constructivas del edificio.

(1897), 468; E. HÜBNER, Scriptionum Hispaniae christianarum supplementum, Berlín, 1900, p. 107; M. GÓMEZ MORENO, Iglesias Mozárabes, p. 141; V. GACÍA LOBO, Las inscripciones..., pp. 64-65; A. MARTínez TEJERA, El templo..., pp. 61 y ss. En los últimos años Maurilio PÉREZ GONZÁLEZ ha realizado un estudio de la misma buscando una nueva dimensión literario/ lingüística al texto y su relación con otros tres epígrafes estrechamente relacionados con ella ("El latín del siglo X leonés a la luz de las inscripciones", en Actas del II Congreso Hispánico de Latín Medieval. León, 11 - 14 de noviembre de 1997, Vol. I, Coord. Maurilio Pérez González, León, 1998, pp 157 - 174).

\footnotetext{
${ }^{40}$ Maurilio PÉREZ GONZÁLEZ, “El latín...”, p. 160.

${ }^{41}$ V. GACíA LOBO, Las inscripciones..., pp. 33 - 34.
} 


\section{1. 1. El primer edificio de San Miguel y su ruina}

La primera información que nos ofrece el epígrafe se refiere al nombre del edificio:

Hic locus antiquitus Michaelis archangeli honore dicatus

Se trata de un templo dedicado a San Miguel. Aunque no se exprese nada más que como lugar (locus), creo que en el contexto del epígrafe, y en la expresión "dedicado" (dicatus), resulta obvio que no es otra cosa que un viejo templo que será reconstruido $^{42}$. Cuando llegó aquí el abad Alfonso, no hay duda de que existía una memoria histórica que recordaba su advocación. No tenemos argumentos para saber cual era la causa del recuerdo: ¿por un epígrafe que así lo conmemorase o porque la tradición oral conservase su nombre ${ }^{43}$ A partir de esta advocación, se ha querido especular sobre el carácter de este edificio; un estudio exhaustivo de este tema superaría con mucho la extensión disponible para este trabajo, y no creo que diese resultados satisfactorios, al menos con el material actual. No es necesario indicar, por obvio y conocido, la existencia de su advocación en el período hispanovisigodo y su continuidad en templos de la monarquía astur ${ }^{44}$. Para la cronología que aquí nos interesa, siglos $\mathrm{X}$ y XI, pienso que los ejemplos que recojo a conti-

\footnotetext{
42 Llamado primero locus para recurrir a una cierta riqueza léxica, pues mas adelante, tal como veremos, se le califica de templo/santuario (edis). Como han señalado la mayoría de los especialistas que se han dedicado al tema, se trata de una expresión con intención literaria que aparece también en la inscripción de San Martín de Castañeda: "Hic locus antiquitus - Martinus sanctus honore dicatus" (GÓMEZ MORENO, Iglesias Mozárabes, p. 169.)

${ }^{43}$ Más adelante indicaré la posibilidad que todavía se conservase el ara antigua.

${ }^{44}$ Dentro de la precariedad de las fuentes a este respecto, por lo menos se puede constatar su culto desde el siglo VII como mínimo.
}

nuación ilustran bastante bien las coordenadas del tema. El pequeño oratorio de San Miguel de Celanova tenía, entre otras funciones y significados, una finalidad funeraria $^{45}$. Iglesias estrictamente monásticas, sin otra funcionalidad específica, eran muy habituales en la época, para ello basta con comprobar los cartularios de monasterios leoneses ${ }^{46}$. Tampoco faltan en tierras leonesas otras iglesias dedicadas a San Miguel que por entonces estaban abandonadas desde antiguo, tal como sucede con el templo de San Miguel en el valle de Fontecha que Pedro Fernández restauró ${ }^{47}$. Como conclusión, diría sobre la función de este templo de San Miguel en su origen que todo es posible, dado que nuestro conocimiento del mismo se reduce a la noticia que el epígrafe nos trasmite. A partir de aquí, todo lo que se ha dicho a este respecto no deja de ser una especulación absolutamente gratuita.

\footnotetext{
-
}

${ }^{45}$ Función y significado de este pequeño oratorio orensano fundado por san Rosendo ha sido minuciosamente estudiado por Manuel NÚÑEZ RodRÍGUEZ, San Miguel de Celanova, Xunta de Galicia, 1988. Ampliando la idea del trabajo de Nuñez, con nuievos datos del entorno del edificio, véase el trabajo de Francisco SINGUL, "Simbología del espacio. San Miguel de Celanova y su entorno", en El legado del santo, pp.146 - 155. Como es bien sabido, la advocación al arcángel Miguel de altares en las torres es una constante en la tradición cristiana que llegaría a tener un enorme desarrollo a partir de la arquitectura templaria carolingia.

${ }^{46}$ Simplemente por poner un ejemplo en un territorio extremo, permítaseme citar aquí el de San Miguel de Silos en tierras burgalesas (I.G. BANGO TORVISO, "La iglesia antigua de Silos: del prerrománico al románico pleno", en Románico en Silos. IX Centenario de la consagración de la iglesia y claustro, Abadía de Silos, 1990, pp. 317 - 376, esp. P. 323).

${ }^{47}$ El presbítero Fernández, en el año 1069, hace donación a Santa María de León "de ecclesia uel cimiterio Sancti Micaelis Arcangeli quos manibus meis restauraui siue edificaui de stirpe antiqua desertum" (José Manuel Ruíz AsEncio, Colección documental del Archivo de la Catedral de León. IV (1032 - 1109), León, 1990, doc. $\mathrm{n}^{\mathrm{o}}$ 11163, p. 400. 
De su forma nada se nos dice, pero sí se pone un especial énfasis en informarnos que se trataba de una obra pequeña:

\section{brevi opere instructus}

No deberíamos hacer mucho caso al hecho de calificar la obra de pequeña (brevi opere). Es una expresión común en los textos que constatan una restauración o renovación de un viejo edificio, pues es la forma de sobrevalorar la obra reciente que se acaba de hacer. Los textos y la epigrafía de la época son muy ricos en ejemplos de este tipo.

La frase siguiente nos explica que este edificio, como tantos otros que hemos comentado en la introducción de este artículo, había caído en ruinas:

\section{post ruinis abolitus}

Es evidente que nada se nos informa sobre la causa de su ruina. Es probable que debamos atribuirla, como otros casos de su entorno, a su abandono por la invasión islámica, aunque en este no se explicite como en otros ejemplos bien conocidos. Hay dos circunstancias más que podrían justificar su ruina, el abandono por el descenso demográfico que en el territorio se venía produciendo desde tiempos romanos o el provocado por la invasión que muy pronto se convirtió en tan crítico que trasformó el territorio en un espacio desarticulado administrativamente.

Desde que se arruinó permaneció mucho tiempo derruido:

\section{diu mansit dirutus}

Habiendo especulado previamente sobre las causas de la ruina, es lógico que, sin otro tipo de información, no nos atrevamos a precisar la cronología expresada con el adverbio diu, tan sólo deberíamos contentarnos con decir "mucho tiempo" ${ }^{48}$.

\subsubsection{Del abad Alfonso, su origen y su regla}

Permaneció en esta situación hasta que (donec) llegó el abad Alfonso con sus compañeros procedente de Córdoba:

\section{donec Adefonsus abba cum sociis adveniens ad Corduvensi patria}

Nada sabemos en concreto de este abad cordobés. El y sus compañeros constituyeron una de tantas comunidades de monjes cordobeses llegados a tierras leonesas durante el reinado de Alfonso III $^{49}$. Al mismo tiempo, o poco antes, un abad Alfonso "cum sociis de Spania" se había establecido en Sahagún ${ }^{50}$. San Martín de Castañeda era renovado en el año 921 por un abad llamado Juan procedente de Córdo$\mathrm{ba}^{51}$. Las migraciones de simples cristianos, no ya solo de monjes, procedentes de Córdoba está atestiguada por nombres de topónimos del tipo Villa de Cordobeses ${ }^{52}$.

Se ha querido dar una gran importancia a la expresión "cum sociis", que tan

\footnotetext{
${ }^{48}$ Recuérdese a este respecto que hemos podido encontrar referencias a "destrucción por los paganos" o "doscientos años o más".

${ }^{49}$ Un planteamiento general sobre la presencia de monjes cordobeses en tierras del reino leonés, con los datos conocidos, ha sido realizado, sin grandes modificaciones hasta ahora, por GómEZ MORENO, Iglesias Mozárabes, p. 106 - 107. Datos que fueron reasumidos en su momento por E. LEVI PROVENÇAL desde la óptica islámica (Historia de España IV. España Musulmana, 711 - 1031. Instituciones y Arte, Madrid, 1973, pp. 118 y ss.

${ }^{50}$ En estos términos se refieren a este Abad dos diplomas manipulados de Ramiro II (José María MíNGUEZ FERNÁNDEZ, Colección diplomática del monasterio de Sahagún, León, 1976, ํㅡ 97 y 98). Algunos estudiosos llegaron a identificar, sin el más mínimo apoyo documental, este abad con el Alfonso de Escalada.

${ }^{51}$ Gómez MORENO, Iglesias Mozárabes,, pp. 168-169.

${ }^{52}$ La colección diplomática de Sahagún recoge esta villa en cuatro documentos del siglo $X$ (MínGUEZ FERNÁNDEZ, Colección diplomática..., nº 80, 87, 247 y 248).
} 
sólo hemos querido traducir con su significado más genérico: compañeros. A partir de una interpretación más o menos literaria se ha propuesto una versión del término adecuada al traslado mismo de los monjes expatriados: comitiva, compañeros de viaje, familias enteras que acompañando a los monjes repoblaban el territorio del entorno de la nueva fundación monasterial. Incluso no falta quien, a partir de él, pretende identificar la regla monástica que practicaban Alfonso y sus acompañantes. Obsérvese que la expresión es la misma que se da a los compañeros del abad Alfonso de Sahagún. La palabra socius significa compañero y puede utilizarse como adjetivo o sustantivo. De esta manera suele figurar en los documentos una institución que se conoce como "colegio", "congregación", "toga", "collatio" de fratres o de sorores, es decir hermanos o hermanas. Sin duda estos son, de todo el colectivo de gentes que viven en un monasterio bajo el régimen o gobierno del abad, los únicos que pueden considerarse monjes propiamente dichos ${ }^{53}$. Luego la palabra socius puede adjetivar a cualquier miembro de la comunidad que se considere camarada o compañero. Así se habla de "compañeros frailes" ${ }^{\prime 54}$. En otras ocasiones la comunidad existente se subdivide en: "clérigos, frailes -hermanos- y sacerdotes ${ }^{55}$.Sin embargo el significado genérico que hemos señalado al principio se puede constatar perfectamente en la continuidad monástica

\footnotetext{
${ }^{53}$ Durante el siglo $X$, las comunidades dúplices se suelen denominar colegio de fratres et sorores. En aquellos momentos a las mujeres no se las suele denominar monjas: la abadesa de Piasca gobierna un "collegio sororum et monachorum qui ibidem peragentibus vitam monasticam" (Idem, , doc. no 96).

${ }^{54}$ Año 943: "Gomessani abati cum sociis fratribus tecum"; año 946, idem; año, 950 (Antonio UBIETO ARTETA, Cartulario de San Millán de la Cogolla (959 1076), Valencia, 1976 , documento $\mathrm{n}^{\mathrm{o}} 30$, p 45 ; doc. 41 , p. 57 ; doc. 57 , p. 71).

55 "Gomessano abbati omnisque clericis, fratribus et sacerdotibus", año 957, (Idem doc. $\mathrm{n}^{-}$73, p. 86).
}

del mismo monasterio de Escalada. El epígrafe funerario del abad Domingo Martín, del año 1014, y el llamado epígrafe del "honor de San Miguel", del año 1050, son un perfecto paradigma a este respecto. En el primero se nos dice que el citado abad quiso ser enterrado por sus hermanos: “...Domenicus Martini, presbiter, abba, qui fratres velit sepultare ${ }^{\prime \prime 5}$. Salta a la vista que el abad desea ser enterrado por sus iguales, sus hermanos. El siguiente epígrafe es mucho más explicito, pues recoge los dos términos: "Sabaricus aba cum ómnibus fratribus et sociis suis... sectantes" ${ }^{\prime 57}$. Es decir los que siguen la disciplina del abad Sabarico en San Miguel son los frades y los socii.

Realmente los socios (socii), en el caso concreto de una comunidad monástica, no son otra cosa que la heterogénea población del monasterio. En ella se incluyen hermanos (frades), presbíteros, religiosos, conversos/novicios, criados, siervos, etc. Habitualmente la documentación monasterial tan sólo suele separar, de manera casi institucional, a los frades del resto de este complejo grupo.

Nada hay en la inscripción que estamos analizando y en la documentación del monasterio de Escalada correspondiente al siglo $X$ que nos permita afirmar que tipo de regla practicaban. El considerarles benedictinos por parte de Yepes no es otra cosa que su deseo de magnificar la orden que el estudia ${ }^{58}$. Como monasterio del monacato hispano, la regla en sí misma ocupa un segundo lugar frente al régimen que les impone el abad en el momento del pacto ${ }^{59}$.

${ }^{56}$ V. GARCíA LOBO, Las inscripciones..., nº 10, p. 67.

${ }^{57}$ Idem, no 11, pp. 68-69.

${ }^{58}$ Fray Antonio YEPES, Crónica General de la Orden de San Benito. II, edic. Fray Justo Pérez de Urbel, Madrid, 1960, p. 102.

${ }^{59}$ Como ya he tenido ocasión de explicar en otros trabajos, para la organización concreta de la topografía monasterial será decisivo el régimen que imponga el 


\subsubsection{Primera restauración del edificio}

Al llegar el abad Alfonso con sus socios se encontraron el edificio caído, procediendo entonces a levantar la ruina del templo:

\section{edis ruinam erexit}

Aunque no se explican los detalles de la expresión "levantó la ruina", es evidente que no consistió en una gran obra, pues más tarde se sienten muy orgullosos de las obras que realizarán no dudando en fijar para "tan importante trabajo" una duración de doce meses. Como he explicado en la parte introductoria de este artículo, refiriéndome a estas y otras obras de restauración de edificios antiguos en esta época, el trabajo debió limitarse a levantar los tejados, quitar los escombros de su hundimiento y asegurar ciertas partes de la infraestructura de soporte ${ }^{60}$.

\subsubsection{Bajo la protección regia}

La cronología de estos sucesos tuvo lugar bajo el reinado del monarca Alfonso III (866 - 911) según nos explica el mismo epígrafe:

\section{sub valente sereno Adefonso principe}

El texto no deja lugar a dudas sobre la cronología del suceso: durante el reinado de este monarca. Es imposible fijar más la datación. Sí puede dar lugar a discusión la

abad que en todo caso tendrá en la regla un referente de práctica espiritual y de lo que podría ser considerada una especie de scala claustralium (Isidro G. BANGO TORVISO, "La imagen del monasterio hispano. Algunas reflexiones sobre su estructura y significado", en $E l$ Monacatp en los Reinos de León y Castilla (Siglos VII XIII) X Congreso de Estudios Medievales, 2005, León, 2007, pp. 173 - 212, espec. pp. 175 - 184).

${ }^{60}$ Parece lógico minimizar esta restauración, pues los monjes de Castañeda no dudaron en expresar de manera categórica que su restauración de la ruina de su templo se realizó desde los cimientos:"edis ruginam a fundamine erexit" (GÓMEZ MORENO, Iglesias Mozárabes, p. 169) exacta interpretación de la expresión "sub valente". Para Gómez Moreno significa "poderoso" 61 . Y de la misma opinión es Armando Cotarelo, quien traduce la totalidad de las palabras así: "en tiempo del poderoso y serenísimo príncipe Alfonso" ${ }^{62}$. Aunque la traducción de García Lobo es libre y literaria, "bajo el eficaz patrocinio del rey Alfonso", es muy posible que sea la más acorde con la verdadera intención del escriba. De esta manera el patrocinio que se podía deducir del participio presente de valeo (valente), vendría de la idea de "siendo valedor" $^{\prime 63}$. Así esta obra se realizó con el respaldo del monarca, mientras que las otras posteriores, tal como tendremos ocasión de comentar, no contaron con más ayuda que las propias de la comunidad.

\subsubsection{Aumento del número de los monjes}

El epígrafe continúa su historia informándonos de nuevas obras en San Miguel. Se nos dice que había aumentado el número de los monjes:

\section{Monachorum numero crescente}

En sentido estricto, solo se refiere el aumento de los monjes, no del resto de la comunidad de "socios". Nada se nos dice del número de personas que constituían esta comunidad ${ }^{64}$. Habitualmente se ha

-

${ }^{61}$ GÓMEZ MORENO, Iglesias mozárabes, p. 141.

${ }^{62}$ Armando COTARELO VALLEDOR, Historia crítica y documentada de la vida y acciones de Alfonso III el Magno, último rey de Asturias, Madrid, 1933, p. 509.

${ }^{63}$ Es un participio del mismo tipo que acompaña al nombre del monarca en los documentos más característicos de esta época (regnante, concurrente, etc).

${ }^{64}$ Aunque se han citado cifras como 204 monjes para el monasterio de Cardeña del año 921, o ciento cincuenta para el monasterio de San Pedro de Arlanza del 969, José Ángel GARCíA DE CORTAZAR considera que los más numerosos deberían contar con un número de monjes que no alcanzaría la cifra de cincuenta ("La colonización monástica en los reinos de León y Castilla (siglos VIII a XIII): dominio de tierras, señorío de hombres, control de almas", en El Monacato..., pp. 19 -20). En todo caso, sobre todas estas cifras y las que 
interpretado este aumento de la población monacal como la causa para una ampliación de la superficie de la topografía monasterial (tanto de la iglesia como de las dependencias de los monjes). Aunque se pueda deducir esto, me parece evidente, por lo que comentaré a continuación, que aquí se está aludiendo a la consolidación de una comunidad más importante por el número de sus monjes que le permitirá realizar, con sus propios medios y sin el apoyo regio que anteriormente se había expresado explícitamente, obras de embellecimiento ornamental.

1.1.6. El templo enriquecido con una bellísima decoración

A continuación se nos habla de nuevas obras realizadas en el templo:

demum hoc templum decorum miro opere a fundamine exundique amplificatum erigitur

Desde mi punto de vista, estas palabras encierran el verdadero significado del trabajo realizado, sin embargo la traducción que se ha venido haciendo hasta ahora no me parece que haya sido correcta. Veamos a continuación si podemos poner un punto de luz en su traducción. Finalmente (demum) se erige este templo decorado (decorum amplificatum) por todas partes con obra admirable hecha de nuevo. Aunque se pudiera traducir amplificatum de forma literal, ampliado, es indiscutible que el énfasis del texto se pone en la decoración y que esta ha sido hecha de nuevo (decorum miro opere a fundamine). Contextualizando el verbo amplifico con decorum me parece indiscutible que su más exacta traducción es la que co-

han dado García Villada, Pérez de Urbel, Mattoso, Sánchez Albornoz, etc, debemos ser muy cautos pues en general responden a datos en los que no se especifica el tipo de miembros de la comunidad en el sentido que hemos tratado en el apartado anterior (1.1.2.): fratres, presbiteri, clerici, socii, etc mentan los diccionarios más usuales: embellecer, ensalzar, realzar, etc.

Por lo que yo conozco, esta interpretación no ha sido tenida en cuenta por los que se han ocupado del edificio. Para Gómez Moreno, su traducción sería:"erigióse de nuevo este hermoso templo con admirable obra por todas partes desde sus cimientos" ${ }^{\prime \prime 5}$. No parece tener lógica la libertad que Gómez se ha tomado aquí, repite dos veces a fundamine: por un lado, se interpreta como "de nuevo" y, a su vez, se vuelve a utilizar para decir "desde los cimientos".

Como conclusión diría que la obra llevada a cabo, una vez que la comunidad se ha consolidado e incluso ha crecido, fue enriquecer el edificio con obras ornamentales realizadas de nuevo. La idea de ampliar en superficie viene inducida por haber dicho previamente "Monachorum numero crescente", circunstancia que obliga a repetir términos que no se dice y olvidarse de la correlación del verbo con los sustantivos sobre los que recae su acción.

1.1.6.1. Obra realizada bajo el patrocinio y control de los monjes durante doce meses de trabajo.

Estas obras han sido hechas totalmente (peracta sunt) en doce meses, no por mandato real, ni por opresión del pueblo, sino por la constante supervisión del abad Alfonso y de los hermanos:

non iussu imperiali vel oppresione vulgo, sed abatís Adefonsi et fratrum instante vigilantia duodenis mensibus peracta sunt hec opera

Es muy posible que estas expresiones estén marcando una clara diferencia con la primera parte. Si el establecimiento de la

${ }^{65}$ GómeZ Moreno, Iglesias Mozárabes, p. 141.En los mismos términos se expresa J. FONTAINE (L'Art préroman hispanique II. L'Art mozarabe, La Pierre qui vire, 1977, p. 83). 
comunidad y las obras de habitabilidad se habían producido teniendo como valedor al monarca, ahora no se trataba de órdenes regias, ni de oprimir al pueblo, sino que todo se había hecho a costa de los propios monjes. A este respecto, la mayor importancia de la comunidad hace sentir su poder para emprender obras de mayor empeño. Sin embargo no conviene olvidar que esta expresión, "de realizar una obra con sus propios medios sin ayuda regia ni oprimiendo al pueblo", es un lugar común en la epigrafía y diplomática de la época.

\subsubsection{Datación}

La información siguiente se refiere a la datación de la obra. Durante mucho tiempo su interpretación no ha tenido problemas, existía unanimidad. García Lobo piensa que el año 913 es el del comienzo de las obras, dado que la consagración, según este investigador, habría tenido lugar en noviembre del $914^{66}$. Hay un argumento muy importante a favor de esta propuesta, el 20 de noviembre es domingo, día de la semana recomendado para la consagración, en el 914. Sin embargo el contenido del texto no se expresa en este sentido, es meridianamente preciso en señalar el año 913. Analicemos el tema por partes.

Una vez que se nos ha informado que las obras se han realizado en doce meses etc, se dice textualmente:

Garsea sceptra regni peragens Mumadonna cum regina

Todo esto había ocurrido teniendo García (910 - 914), con la reina Mumadonna, los símbolos del reino (literalmente sería los cetros - sceptra- ${ }^{67}$ ). Es una fórmula muy

\footnotetext{
${ }^{66}$ V. GARCÍA LOBO, Las inscripciones..., p. 36.

${ }^{67}$ Se podría entender que los sceptra se refiere como plural pues se trata del cetro del rey y de la reina. Lógicamente para esta interpretación, que en lo que yo conozco sería excepcional, lo correcto sería que el participio se expresara también en plural peragentes. En
}

habitual en la diplomática de la época para fijar la cronología de los hechos que se recogen en el texto o, al menos el de la realización del testimonio escrito. Las obras se realizaron totalmente en doce meses (duodenis mensibus peracta sunt hec opera): la expresión verbal en perfecto indica con precisión que la acción se ha acabado; el mismo verbo perago significa cumplir, realizar por entero. Así pues, y dada la estructura sintáctica de ambas frases, no veo posibilidad de cuestionar que los doce meses no se cumplieran en su totalidad bajo el reinado de García y Mumadonna.

Algunos epigrafistas no entienden que la expresión de la era figure en renglón aparte según el texto de Risco:

\section{Era DCCCCC LI (año 913)}

Al no conocer el original y no poder precisar si el tipo de letra era diferente, circunstancia que podría indicar un añadido en época posterior, cualquier tipo de explicación no pasa de ser una mera especulación más o menos brillante. Volveré al tema en el apartado siguiente.

\subsubsection{Referencia a la consagración}

Desde mi punto de vista, el texto que viene a continuación es inseparable de la referencia cronológica que acabamos de ver, pues la datación de una consagración no puede carecer de la expresión de la era. El texto dice así:

\section{Sacratumque templum ab episcopum Jena- dium XII Kalendas Decembrium}

Lo que viene a ser: "y el templo fue consagrado el 20 de noviembre por el obispo Genadio". Es decir esta consagración tuvo lugar en 913. Si tenemos en cuenta que las obras se prolongaron durante doce meses, y que la consagración, como es lo más

las crónicas asturianas sceptra se refiere a símbolos del poder del rey. 
lógico se produciría a continuación, el 20 de noviembre, estas debieron comenzar en diciembre del año anterior, todo más en los primeros días de enero del 913.

La ceremonia fue oficiada por Genadio, obispo de Astorga (909 - 920), el 20 de noviembre de 913. Los estudiosos han manifestados sus dudas sobre el hecho que fuese Genadio su consagrante, pues, al ser pontífice astorgano, Escalada no estaba bajo su jurisdicción. Se podría pensar en una invitación extraordinaria por parte del prelado leonés, cosa que no era habitual, pero que tampoco es extraña. Hay también la posibilidad de una sede vacante entre la prelatura de Scemeno y Cixila II que la documentación no nos aclara satisfactoriamente entre el final del 913 y el principio del $914^{68}$. Se ha señalado la presencia real en esta consagración sin otro fundamento que la cita de la pareja real en este epígra$\mathrm{fe}^{69}$, que, como se aprecia claramente, no tiene otra misión que servir de referente político/cronológico del mismo tipo que figura en el aparato notario/protocolario de los documentos.

Aunque este epígrafe no se puede considerar propiamente el de consagración, sí nos suministra la noticia del acto informándonos del ministro celebrante. Se conservan tres aras, correspondientes a cada uno de los ábsides, que la mayoría de los especialistas consideran que han sido realizadas al mismo tiempo y que debieron corresponder a esta fecha de consagra-

\footnotetext{
${ }^{68}$ A todo esto había que añadir la complejidad de la actividad de los obispos en este período, tal como ha estudiado Dolores MARIÑO VEIRAS "Obispos en la Iglesia Regio-Aristocrática...".

69 Justiniano RODRÍGUEZ FERNÁNDEZ, Reyes de León, Burgos, 1997, pp. 27 y ss. Podría haber estado presente el monarca, pero para ello necesitaríamos algún tipo de noticia documentada, la presente, por sí mismo, no es ni indicativa siquiera.
}

ción ${ }^{70}$. La que pertenece al ábside septentrional (Láms.5 y 6) según la inscripción contaba con las siguientes reliquias: + Hic sunt reliquie recondite / sancte marine / et sancte cecilie / et san(c)ti aciscli / et sancti cristofori / et sancte columbe. El texto del ara meridional (Láms. 7 y 8) enumera las siguientes reliquias: + Hoc in altare sont reliqvie / sancti emiliani pr(es)b(ite)ri / sancti bartolomei ap $(o) s(t o) l i$ / sancti stefani levite / sancti martini episcopi. La que ocupaba el ábside central contiene una relación más amplia (Lám. 9 y 10), lo que obliga, por motivo de espacio, a aumentar el número de las abreviaturas: + Hic sunt reliqviae recondite / id s(vn)t de cruore d(omi)ni de ligno domini / de sepulcro d(omi)ni $s($ an $) c(t)$ e marie $s(a n) c(t) o r(u m)$ petri et pauli I $s(a n) \mathcal{C}(t) i$ andre ap (o)st(o)li $s(a n) c(t) i$ tome ap(o)st(o)li s(an)c(t)i adriani / $s(a n) \mathcal{C}(t) i$ ivliani $s(a n) c(t)$ or $(u m)$ cosme et damiani.

\subsection{El arco del abad Sabarico}

La siguiente constatación documentada de una obra en San Miguel nos la ofrece la puerta situada en el muro meridional del templo, también conocida como "arco de Sabarico" (Lám. 11). Se trata de un arco de herradura achaparrado, algo deforme y factura bastante grosera que constituye la única puerta medieval existente en la actua$\operatorname{lidad}^{71}$. Cada una de las dovelas tiene trazadas con bermellón, sobre sus dovelas, letras en orden alfabético, idénticas a las de otra inscripción existente en Escalada y que corresponde al año 1040. Por esta razón, Gómez Moreno piensa que se procedió a escribir estas letras en los sillares para no equivocar el orden de piezas al trasladar el arco de otro sitio, razón por la que el erudito historiador granadino deducía "que este arco es de los más viejos de Escalada, que

${ }^{70}$ GÓMEZ MORENO, Iglesias mozárabes, p. 159; V. GARCíA LOBO, Las inscripciones..., no 5, 6 y 7.

${ }^{71}$ Sobra las puertas originales y sus trasformaciones vid mas adelante el apartado 2 de este mismo articulo.
} 
Sabarico lo repuso, llevándolo quizá de otro lugar, y así se explica que veinte años después, al escribir el epitafio, lo reputasen obra suya" $^{\prime 72}$. La relación de este arco con el citado abad consta en su epitafio, que está situado en el salmer izquierdo del mismo. En el epígrafe se nos informa de los siguientes hechos:

Ob(it) Sabaricus abba / die II ${ }^{\underline{a}}$ f(eria) VIII $k(a) l($ en $) d(a)_{s}$ / n (ovem)br(i)s era LXL cu(m) / VII ${ }^{a} p$ (ost) m(i)l(lesima) / ipse f(e)c(i)t iste $\operatorname{arcu}(m)$ / a suo cabo iace / nom abea p(a)rte cum / Xr(ist)o om(o) q(u)i d(e) isto / loco sakare amen

El abad Sabarico murió el lunes 25 de octubre del año 1059. También se nos dice que el mismo construyó este arco, a cuyo pie está enterrado. Termina la inscripción en estos términos: quien se atreva a sacarlo de este lugar no tenga parte con Cristo. Este mismo abad figura en el llamado epígrafe del "honor de San Miguel", datado en el año 1050, que se encuentra sobre una placa situada sobre el arco. Para Martínez Tejera el arco sería trasladado aquí entre 1047 y 1059, años que enmarcan la cronología que tradicionalmente se atribuye al abadiato de Sabarico $^{73}$. Como tendremos oportunidad de comentar más adelante, creo que este arco/puerta fue realizado en el momento que constata el epígrafe y si esto es así, lo más probable es que el arco estuviera desde su origen aquí mismo.

\subsection{La supuesta restauración del año 1088}

En altar principal se introdujo una nueva reliquia, la del apóstol Santiago. Como el ara había sido diseñada para el título de las reliquias originales, la nueva hubo de consignarse de manera arbitraria y

72 GÓMEZ MORENO, Iglesias mozárabes, p. 153.

${ }^{73}$ Para este autor el arco correspondería a una puerta situada en el centro del hastial occidental y Sabarico lo único que hizo fue trasladarla a este nuevo emplazamiento en la fachada meridional del templo (MARTÍNEZ TEJERA, El templo..., pp. 125 - 126). con no muy buena letra en el espacio disponible entre la cenefa y el borde del tablero (Láms. 12). El texto dice así: $+s(a n) c(t) i$ iacobi ap(o)st(o)li fr(a)t(e)r ioannis. La enorme popularidad que el culto jacobeo alcanza a partir de la segunda mitad del siglo $X$ hace que desde entonces muchos templos quieran prestigiarse con reliquias de Santiago ${ }^{74}$. Para Gómez Moreno el tipo de letra es similar al de la inscripción de Boñar del año 980, sin embargo, pese a esta información tan categórica no tiene inconveniente en atribuirle la cronología del epígrafe de los cantos del $\mathrm{ara}^{75}$.

Ocupando los cuatro cantos de la inscripción se dispone el siguiente letrero en un solo renglón (Lám. 13):

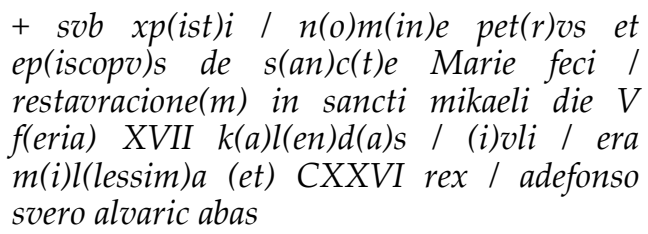

La trascripción, salvo en algunos detalles, ha sido bastante bien interpretada ${ }^{76}$.

\footnotetext{
${ }^{74}$ La presencia de una reliquia de Santiago o una imagen suya no debe llevarnos al error de interpretarlo en función de las rutas jacobeas. Culto y camino de peregrinación son dos efectos consecuentes con la popularidad del santo, pero entre sí mismo no tienen porque relacionarse directamente. Esta confusión produce graves distorsiones en la interpretación de la historia y de la cultura. Lo más grave a este respecto, es cuando ciertas autoridades de "política culturalista" utilizan de manera torticera este tipo de argumentos con fines de prestigio y promoción turística.

${ }^{75}$ GÓMEZ MORENO (1919), p. 160, notas 3 y 4 . La diferencia de letra debe ser la causa que García Lobo reproduzca el texto de Santiago en la lectura del epígrafe del ara del año 913 (no 7), mientras que las del canto las estudie por separado con su cronología correspondiente ( $\mathrm{n}^{\mathrm{o}}$ 13).

${ }^{76}$ Dejado a un lado los problemas de las interpretaciones de Fita y de Hübner, sin más trascendencia en los trabajos más recientes, será Gómez Moreno el que introduzca un error que ha sido tema de discusión en estudios más modernos. En la referencia de la era introduce un X más ("CXXXVI -1098-), afirmando que con ello se corrige la fecha de diez años antes que
} 
Sin embargo creo que no se acierta en la exacta traducción de esta parte: feci / restavracione $(m)$ in sancti mikaeli die. Gómez Moreno considera que debe referirse a la restauración del altar con motivo de haberse agregado entonces, o poco antes, la reliquia de Santiago ${ }^{77}$. García Lobo habla de una restauración, pienso que en el sentido de una obra, en la iglesia: "hice una restauración en San Miguel..." ${ }^{78}$. Martínez Tejera no sólo insiste en el planteamiento de Gómez Moreno sino que considera que comportó el cambio de soporte del altar, la presencia de dos sepulchra para las reliquias (antiguas y nueva) y sobre todo el cambio de rito, la vieja liturgia hispana daría paso a la romana ${ }^{79}$.Dejando a un lado errores mínimos sobre la exacta trascripción léxica (persona verbal, los casos, etc), lo más importante para mi se refiere a dos aspectos del contenido. El día de la ceremonia y la correcta interpretación del término restauracione.

El día de la restauración fue elegido especialmente, pues se trata del mismo día que, según el autor de epígrafe, se celebraba la festividad de san Miguel: "en el día de san Miguel". Es evidente que la preposición in puede regir ablativo o acusativo, pero nunca genitivo (sancti mikaeli). Esta preposición se refiere a die, es decir "en el día", teniendo entre la preposición y el sustantivo en ablativo el correspondiente genitivo según fórmula muy habitual. Se podría argumentar con el error en la declinación

erróneamente se difundía por entonces (Catalogo Monumenta.... p. 109). El mismo autor enmienda su error, suprimiendo el numeral $\mathrm{X}$ en su célebre obra sobre arquitectura mozárabe (Gómez MORENO, Iglesias mozárabes, p. 160).

${ }^{77}$ Algunos historiadores afirman que Gómez Moreno atribuye esta restauración para conmemorar la construcción de la torre y la capilla románica. No es cierto que diga exactamente esto, sino que estas obras románticas deben coincidir con la cronología expresada en el ara.

${ }^{78}$ V. GARCía LOBO, Las inscripciones..., p. 70.
${ }^{79}$ MARTíneZ TEJERA, El templo..., pp. 96 - 97. del nombre Mikael, lógicamente sería mikael/mikaelis, pero suele ser normal que este tipo de nombres se contamine del sustantivo que le acompaña (sanctus mikaelus). Los ejemplos que se podían aportar son numerosísimos, pero en este caso nos bastaría, por su proximidad en el tiempo y en el espacio, la ya citada inscripción del llamado "honor de San Miguel", donde se escribe HONOREM SCI MICAELI ARCANGELI ${ }^{80}$. $\mathrm{Si}$ creo que no hay duda en esta interpretación, también es cierto que la identificación de la festividad del santo con el 15 de junio no coincide con la fecha más difundida por los calendarios romanos e hispanos: 29 de septiembre $^{81}$. No parece que se haya producido un error de interpretación del lapicida, pues no se trata de un solo numeral sino incluso del mes. Me inclino a pensar que hay alguna circunstancia que llevaba a celebrar solemnemente esta festividad en Escalada un día especial ${ }^{82}$. Como el 15 de junio de 1088 caía en jueves, algunos especialistas, considerando que la tradición litúrgica hispana remitía a los domingos la ceremonia de la consagración, han manifestado sus dudas. La celebración de San Miguel en esta fecha podría justificar la excepción, sin embargo es evidente que en la diócesis leonesa ya se practicaba en este momento los usos de la nueva liturgia que no requería la obligación de su celebración en domingo. El mismo obispo Pedro de León consagra la iglesia del monasterio de San Juan de Valdemora el 14 de mayo de 1090, día que tampoco coincidía en domin$\mathrm{go}^{83}$.

-

${ }^{80}$ V. GARCÍA LOBO, Las inscripciones..., nº 11, p. 68.

${ }^{81}$ Angel FÁBREGa GRAU, Pasionario Hispánico (Siglos VII - XI), T. I, Madrid/Barcelona, 1953, p. 219.

${ }^{82}$ Estas celebraciones concretas y distintas a la más generalizada eran relativamente frecuentes en diferentes santuarios dedicados al arcángel tanto en Oriente como en Occidente.

${ }^{83}$ José Manuel Ruíz ASENCIO, Colección documental... (1990), doc. no 1248, pp. 535 - 536. 
1.4. Etapas constructivas a partir de la información documental

A partir de lo que venimos comentando hasta aquí, podemos deducir que al menos se pueden documentar las siguientes fases constructivas:

1a. Existe un viejo edificio de culto abandonado, que permite, sin que se hagan obras reseñables, utilizarlo por la comunidad recién llegada.

$2^{\text {a }}$. Cuando el monasterio se ha consolidado con un aumento de la población de los monjes, se realiza una obra que dura apenas doce meses (913). Sobre su contenido y originalidad, la información es muy precisa: se embellece el edificio con elementos decorativos realizados de nuevos.

$3^{\text {a }}$. El abad Sabarico realiza el arco que sirve de puerta en la fachada meridional del templo (1047 - 1059).

$4^{a}$. La restauración del año 1088, dada la grosería de su epigrafía no debe corresponder con una obra de cantería importante. También es muy posible que se deba más a una imposición de reliquias o simplemente a una reconciliación ritual.

1.4.1. La actual fábrica prerrománica de San Miguel y sus fases de construcción

Mientras que el material documental analizado en el apartado anterior es básicamente la totalidad del que conocemos en la actualidad, lo que vamos a realizar a continuación no son más que unos breves comentarios sobre lo que apreciamos a primera vista, contrastado con lo que la historiografía arqueológico-artística del edificio nos ha enseñado. Para futuros estudios serán imprescindibles una buena fotogrametría del monumento, análisis de los materiales y unas meticulosas prospecciones paramentales en aquellos lugares en los que han tenido lugar añadidos o transformaciones de la fábrica original.
Lo primero que apreciamos en el edificio es una diferenciación manifiesta de la concepción paramental de los muros que definen sus distintos volúmenes: los muros perimetrales del ábside septentrional, los de las naves colaterales y todo el cierre occidental son de mampostería; el ábside central, lo que se ve del colateral meridional y las arquerías de los dos intercolumnios así como los muros de cierre de las naves con el crucero, incluida la "puerta del coro" o mal llamado iconostásis o cancel alto (Lám. 14) , también son de de buena cantería; sobre los intercolumnios los muros se continúan en ladrillo. Acerca del ábside colateral meridional resulta difícil definirse, pues en lo que se aprecia parece como si hubiera sido rechapado con cantería al realizarse la obra románica, aunque no me atrevería a afirmarlo rotundamente, pues la trabazón de algunas hiladas da la sensación de original $^{84}$. El pórtico lateral que corre a lo largo de la fachada meridional, realizado en piedra, muestra claramente dos fases muy diferenciadas, que incluso a su vez fueron remodeladas más tarde: $1^{\underline{a}}$ ) la constituida por los siete arcos occidentales (Lám. 15); $2^{a}$ ) el resto de la arcada hasta integrarse en la construcción románica oriental (Lám. 16).

En el contexto de esta fábrica arquitectónica conservada es necesario situar lo que podría haber sido el templo de San Miguel original. La excavación arqueológica no ha constatado una subestructura con la que se pueda identificar. La lógica parece inducirnos a considerar que este edificio se encuentra en gran parte asumido en lo actualmente conservado. Se podría atribuir a esta parte todos los muros perimétricos de mampostería, aunque dado lo torturado de sus paramentos tanto de épocas que po-

\footnotetext{
${ }^{84}$ Este es uno de los lugares donde se pueden realizar con cuidado prospecciones murarias y otros métodos de análisis sin que sufra la integridad del monumento.
} 
dríamos considerar históricas, como las intervenciones "restauradoras" del último siglo, no nos permiten, por ahora, ser del todo contundentes en mayores precisiones.

Dejando a un lado la problemática de estos muros perimetrales, serán los capiteles de los dos intercolumnios que forman las tres naves hacia el occidente del pórtico del coro $(1-10)$, todos ellos reaprovechados y sin ningún criterio de similitud, los que constituyan el bloque del edificio antiguo. El reaprovechamiento de este material es muy heterogéneo y de difícil clasificación: un tablero con una inscripción funeraria, obra de los siglos $\mathrm{IV}$ o $\mathrm{V}^{85}$, capiteles claramente tardorromanos y otros que posiblemente sean de igual clasificación pero para los que carecemos de paralelos precisos (Láms. 17 y 18). De material indudablemente romano reaprovechado en la construcción de Escalada son también testimonios algunos ladrillos encontrados en los muros que en la actualidad se desconoce su paradero ${ }^{86}$.

De manera muy general, tendríamos un gran bloque que obligatoriamente adoptaría una solución arquitectónica determinada. Tal como podríamos deducir hoy, dado lo conservado, habría un edificio de tres naves con muros perimetrales en mampostería y con los intercolumnios separadores de las naves en arcos de herradura de cantería y columnas reaprovechadas. La solución no es extraña al menos desde la arquitectura tardorromana. Para elevar la nave central sobre las colaterales se erigieron unos muros, que hoy son de ladrillo rojo (Lám. 15 y 19). Gómez Moreno consi-

\footnotetext{
85 Dedicada a Valería, esposa de Montano (V. GARCÍA LOBO, Las inscripciones..., no2, p. 60).

86 Son ladrillos estampillados (Legio VII Gemina Philippiana) "que fueron encontrados y sacados del muro del templo mozárabe de San Miguel de Escalada por el arquitecto J. B. Lázaro cuando hacia 1897 se hizo cargo de las obras de conservación" (Idem, n ำ1, p. 59).
}

dera que este muro de ladrillo es la misma época que el resto del edificio ${ }^{87}$. Los ocho ángulos que forman las cornisas del cuerpo de la nave central y de las colaterales cuentan con un elemento común que da gran unidad a estas partes altas: el tipo de modillón (Láms. 20 y 21). Aunque están muy rotos, todavía se puede reconstruir perfectamente su perfil, forma y decoración. Seis o siete baquetones, de tamaño decreciente, y dispuestos en diagonal recta. La decoración de los extremos es muy convencional desde la protohistoria hasta la plenitud del románico: espirales, rosetas, etc. El perfil recto y su factura podrían considerarse arcaizantes, pero tampoco sería extraño que fueran muy antiguos ${ }^{88}$. No tenemos en toda la línea de aleros ningún testimonio de modillones a lo largo del mismo, tanto en las naves colaterales como de la nave central. La norma en los edificios de esta época es que todo el alero tuviera modillones, tal como podemos apreciar en el ábside central de este mismo monumento o en cualquier otro edificio bien conservado de esta época. Estos modillones de esquina conservados ocupan el lugar lógico que debiera ocupar el friso de esquinillas, lo que me induce a creer que son anteriores a este friso y al mismo muro de ladrillo. Aunque sin determinadas prospecciones murarias, lo que digo a continuación no es más que una hipótesis: existió un muro previo que contaría con modillones como los conservados en las esquinas con los que formaría la línea del alero, y sin tener friso de esquinillas. El muro de ladrillo actual correspondería a una reforma de la cubierta imitando ciertas partes del cornisamiento de la cabecera, realizado tardíamente a causa de un hun-

\footnotetext{
${ }^{87}$ Gómez MORENO, Iglesias mozárabes, p. 151.

${ }^{88}$ Recuerdan por su rudo esquematismo y el perfil casi recto de los baquetones a los del templo cántabro de San Román de Moroso, construcción de buena cantería pero de factura muy ruralizada (I. G. BANGO TORVISO, El prerrománico...., p. 365).
} 
dimiento de la cubierta. Gómez Moreno piensa que los modillones no faltan sino que sobresalían las vigas de madera de la armadura describiendo como es lógico la forma baquetoneada correspondiente. Consideraba que los modillones que faltan "constituían los extremos de las alas del tejado, cuyos demás elementos eran de madera según dos ejemplares de modillones descubiertos por el señor Lázaro" $)^{89}$. En la actualidad sólo se conserva uno en el Museo de León. Pudiera ser esta la interpretación, pero desde mi punto de vista, dado su grosor, es muy difícil que se refiera vigas correspondientes a la longitud que se requiere para esta nave central, me inclino más que sirvieran para las vigas que formaran la cubierta y el correspondiente alero del pórtico

Hay una segunda parte del edificio que, al menos por el exterior, muestra una gran unidad: el ábside central. Como puede apreciarse (Lám. 22), ha sido realizado con un paramento exterior de sillería de arenisca, limitado por dos estribos. Para Gómez Moreno se trata de una obra del siglo XII, que sin embargo respetó el alero de una obra anterior $^{90}$. Sobre esta afirmación tengo serias dudas, que no despejaré definitivamente hasta un análisis en profundidad de todo el paramento de este ábside central y su continuidad sobre el colateral hasta la misma torre ${ }^{91}$. Resulta difícil creer que el alero fue mantenido procedente de una obra anterior. El friso de esquinillas y la organización de metopas y modillones encajan tan exactamente sobre el actual volumen que resulta casi imposible que sean readaptados en una obra ampliada a partir de otra preexistente para la que había sido

\footnotetext{
${ }^{89}$ GÓMEZ MORENO, Iglesias mozárabes, p. 152.

${ }^{90}$ Idem, p. 149.

${ }^{91}$ Existen tales desajustes que sin una limpieza general y un minucioso estudio fotogramétrico cualquier tipo de afirmación resulta bastante gratuita.
}

prevista esta solución de cornisamiento. De lo que no hay duda es que el alero de este ábside y el de las naves, aunque pretenden mantener el mismo esquema (friso de esquinillas sirviendo de base a los modillones) responden a dos criterios distintos y a dos tipos de constructores muy diferentes. Mientras que en las naves las esquinillas son de ladrillos entre listeles del mismo material, en el ábside central ambas partes son de piedra Frente a los modillones antiguos, o al menos muy arcaizantes con su prolongado perfil recto, de las naves, los del ábside central (Lám. 23) responden a otro criterio: modillones en curva de nacela muy alta, formando lóbulos convexos. Gómez Moreno está en lo cierto cuando propone para este tipo de modillón una cronología muy lata: desde la época más primitiva de la mezquita de Córdoba hasta las más modernas creaciones moriscas ${ }^{92}$.

Otro aspecto que me gustaría comentar es el de las puertas del edificio original, entendiendo por original el estado que tendría hasta que comenzaron a realizarse obras románicas. Tomando como referencia el plano de las excavaciones de Larrén (Lám. 24), constatamos la existencia de cinco puertas: Puerta A abierta en el muro septentrional, comunicando el exterior con el espacio del coro; puerta $\mathrm{B}$ en el muro meridional, prácticamente en correspondencia con la anterior; puerta $\mathrm{C}$, en el muro meridional, situada en el centro del espacio que forman la tres naves desde el muro occidental y la línea de la porta chori; puerta $\mathrm{D}$, en el muro occidental, abierta a la nave colateral meridional; puerta E, también en el muro occidental, comunicando con la nave central. Seguramente estas puertas no eran las únicas, pero, como ya hemos comentado, el tipo de muro y sus rehacimientos no nos permiten ningún tipo de afirmación.

\footnotetext{
${ }^{92}$ Idem, p. 150.
} 
De la puerta A, lo primero que tenemos que decir es que la forma de jambas rectas que se proyecta en la planimetría se debe a una trasformación moderna, pues en el periodo que aquí nos interesa se habría tenido que construir con un talón a cada lado. Sólo en algunas puertas de época hispanogoda se solucionarían los jambajes rectos tal como vemos aquí. El único testimonio real de esta puerta conservado en la actualidad dos largueros de madera que permitían abrir una puerta adintelada bajo ellos. Para Gómez Moreno se trataba de una entrada a una sacristía ${ }^{93}$.

Para Gómez Moreno, la puerta B sería un postigo moderno, sin embargo su dibujo en planta reproduce un esquema medieval $^{94}$. No corresponde discutir aquí sobre la cronología de esta puerta, pues es evidente que está abierta en un muro que no pertenece a la fábrica original, sus sillares son de una reedificación del muro posiblemente románica como muy temprana. Por esta razón no podemos constatar de manera indiscutible la posibilidad de una puerta en este lugar que se pudiera corresponder con la del muro septentrional. Si así fuera, estaríamos con las puertas A y B (esta última debería estar en el muro original y del mismo tipo que vislumbramos en el muro septentrional -A-) que darían acceso a las características sacristías de la liturgia hispana que definí hace unos años. Como tendré oportunidad de comentar más adelante, el pórtico de siete arcos sería una consecuencia del espacio que ocuparía esta sacristía meridional.

-

${ }^{93}$ Idem, p. 152.

${ }^{94}$ Idem, fig. 57. Al tener sobre la puerta un epígrafe funerario del siglo XVI (V. GARCÍA LOBO, Las inscripciones..., pp. 58 y 86-87), se ha atribuido esta datación, aunque existen otras propuestas debidas a las restauaciones de los siglos XIX y XX (Sobre la problemática cronológica de esta puerta vid. MARTínEZ TEJERA, El templo..., pp. 163 - 164).
La puerta C corresponde al arco realizado por el abad Sábarico según explica su epígrafe funerario, del que ya hemos tratado en el apartado 1.2. Su forma tosca ha confundido a los especialistas que se han ocupado de él, llegando a considerarlo como el más antiguo del edificio. Si analizamos su módulo y la organización de su dovelaje, nos daremos cuenta que se trata de una obra tosca mas que antigua, fruto de unos constructores muy rudimentarios. Si observamos el trazado del arco en relación con el despiezo de las dovelas, comprobamos que es un arco de medio punto cuya herradura se forma con un peralte constituida con dovelas horizontales que recortan la curva de la herradura por el intradós, llegando en algún caso a constituir el peralte un salmer de una sola pieza. En realidad no es más que un simple arco de medio punto. Estamos ante una fórmula de arco tardorromana que se seguirá utilizando durante toda la alta edad media hispana. Solución similar aparece en la mayoría de los arcos de Santiago de Peñalba (Lám. 25) o en la de San Román de Moroso (Lám. 26), obras del siglo $X$, pero todavía seguía estando en vigor en tierras leonesas en el siglo XI tal como podemos constatar en la puerta que daba acceso al cementerio real de San Isidoro de León (Lám. 27). Por otro lado las letras pintadas de las dovelas no sólo sirven para el traslado de un sitio de la fábrica a otro, sino de la lonja donde se trabaja hasta el lugar en el que se colocan; y esta es la función primordial de estas letras en las canterías medievales. Que Sabarico se quisiera enterrar ante la puerta de entrada a la iglesia es algo tradicional en las prácticas funerarias tradicionales para aquellos tiempos ${ }^{95}$. Aunque no cuento con

\footnotetext{
95 El abad Domingo Manso (1000 - 1073) fue enterrado ante la puerta de los monjes en Santo Domingo de Silos por la misma época que Sabarico, con una clara intención de que los monjes lo tuvieran presente al entrar en el templo (Isidro G. BANGO TORVISO, "La
} 
datos suficientes, es un indicio muy claro que estamos ante la puerta de los monjes, con todo lo que esto significa para la organización topográfica de las dependencias monasteriales. Lo que Sabarico dispuso fue hacer un arco que trasformase en más "monumental" el vano de una puerta previa. No hay un solo dato que nos permita cuestionar la exactitud de la información histórica que nos suministra el epígrafe.

La puerta D sólo conserva grandes bloques de piedra que constituían sus jambas y sobre ellas un larguero de madera similar a los que vimos en la puerta A. En los dibujos que representan el vano en planta no se especifica si las jambas están talonadas, pues el arco está totalmente cegado. Gómez Moreno supuso que ante esta puerta se dispondría "según costumbre un zaguán" ${ }^{\prime 96}$. Tal como he estudiado en numerosas ocasiones las puertas de más uso solían estar protegidas por pórticos, muy simples de madera o de piedra con pretensiones monumentales. En la zona leonesa se conocían estos pórticos como cabildos (capituli) desde el siglo X. Solían desarrollarse por una, dos y hasta las tres fachadas de un templo ${ }^{97}$. En Escalada, aunque se han hecho propuestas interpretativas de este zaguán/vestíbulo ${ }^{98}$, es evidente que, si existió, no se articulaba con el pórtico meridional que todavía subsiste. Creo haber demostrado que desde época hispanogoda algunas partes occidentales de iglesias están formadas por una estructura tripartita, siendo la central un lugar de paso, mientras que las

antigua iglesia de Silos...", B,1,2 y p. 349 con notas 180 -182).

${ }^{96}$ GÓMEZ MORENO, Iglesias Mozárabes, p. 152.

${ }^{97} \mathrm{He}$ estudiado el "cabildo" ante la puerta de la catedral de León en esta época (Isidro G. BANGO ToRVISO, "Catedral de León. Desde la instauración de la diócesis hasta...", p. 51).

${ }^{98}$ Martínez ha realizado diversas hipótesis interpretativas de este posible zaguán (MARTínEZ TEJERA, El templo..., pp.112 y ss.). dos laterales constituirían dependencias penitenciales ${ }^{99}$. Para constatar una estructura de este tipo deberemos tener en cuenta la puerta E que analizamos a continuación.

La puerta E se abre también en el hastial de poniente, daba acceso a la nave meridional y en la actualidad está cegada. No está a eje de la nave, sino que se ubica claramente desplazada hacia el sur. Se trataba de una puerta que tenía las jambas talonadas ${ }^{100}$. En los templos organizados topográficamente para la liturgia hispana solo conozco accesos en esta parte del edificio en San Miguel de Lillo, accediendo a las escaleras que ascienden a la tribuna, y en Santa María de Lebeña correspondiendo a sacristías ${ }^{101}$. En ambos casos se trata de dos

\footnotetext{
${ }^{99}$ Estas estructuras tripartitas a los pies del templo son muy características de los edificios asturianos, tal como se aprecia claramente en Valdedios. El espacio central esta destinado a paso, mientras que las cámaras laterales son estancias penitenciales. En la iglesia monasterial que Ludovico Pío realizó en Inden para Benito Aniano se daba una estructura muy similar, aunque en realizdad desconocemos su exacta funcionalidad (BANGO TORVISO, "La vieja liturgia hispana y la interpretación funcional del templo prerrománico", en VII Semana de Estudios Medievales , Nájera, 1997, pp. 61 - 120; El Prerrománico...., pp. 459 y ss.).

${ }^{100}$ En el primer plano publicado de este monumento, realizado por VELÁZQUEZ BOsCO en 1870 (Monumentos Arquitectónicos de España. Provincia de León (San Miguel de Escalada), la puerta se representa con unas jambas abiertas en esviaje. Esta circunstancia nos obligaría a interpretarla como una obra moderna o simplemente con un criterio de representación gráfica decimonónica. Esto último es lo que se ha producido aquí, pues la puerta $C$ también se representa de la misma forma y es evidente que no es así. A partir de entonces, o no se representa como en el caso de Gómez Moreno, o se reproduce atalonada y con las jambas rectas y paralelas como corresponde a una obra altomedieval. El primer plano que la representa así es el de Francisco Valdurieco (Archivo General de la Administración del Estado, Alcalá de Henares), realizado antes de 1884 y reproducido en MARTÍNEZ TEJERA, El templo..., pp. 27 y ss y fig. 8.

101 A este respecto es muy interesante comparar con la disposición occidental de Santa María de Lebeña, donde puertas de igual ubicación daban acceso a sacristías (BANGO TORVISO, El Prerrománico..., p. 351).
} 
accesos simétricos, uno en cada nave colateral, y situados a eje con sus naves respectivas. En Escalada carecemos de información sobre una posible puerta simétrica a ésta, en la colateral septentrional. El desplazamiento de la puerta me inclina a creer que no fue pensada para una construcción occidental tripartita que tuviese, en la parte septentrional, un acceso y dependencia similar. La disposición de esta puerta nos indica que no se abre desde la iglesia, sino desde el interior de la dependencia. Todo parece indicar que no corresponde a una de las dos sacristías típicas de la liturgia hispana, ni tampoco una de las dos dependencias penitenciales. Teniendo en cuenta esto, habrá que pensar que se trata de un ámbito espacial concebido de manera espontánea para un uso indefinido en este momento, cuya exacta cronología desconocemos, pero que en sentido estricto solo podemos calificar de medieval sin más precisión.

Por último nos ocuparemos del pórtico que corre a lo largo del muro meridional del edificio. Un intercolumnio de doce arcos de herradura soporta un tejado a una sola vertiente. Se cierra por la parte occidental con un muro de sillares que forma un ángulo recto, mientras que por oriente la torre ha destruido el muro de cierre, en claro indicio de que esta se ha construido después del pórtico. Gómez Moreno señaló que, aunque el pórtico parece muy unitario, se realizó en dos fases distintas: "los siete arcos occidentales, lindantes con el cuerpo de la iglesia, son lo más antiguo; los cinco restantes fueron añadidos, seguramente, después de hecha la torre, $\mathrm{y}$, aunque imitan a los primeros, la diferencia entre ambos grupos es harto sensible $^{\prime 102}$. Para el primer tramo señala una cronología en paralelo con Santiago de Peñalba, es decir realizada en el decenio 930/940. Para Martínez Tejera el proyecto es

\footnotetext{
${ }^{102}$ Gómez Moreno, Iglesias Mozárabes, , p. 154.
}

unitario y el cambio de formas sólo se debe a un condicionamiento del material reaprovechado, correspondiendo su cronología con la fecha del traslado del arco de Sábarico (puerta C) ${ }^{103}$.

Sin duda el pórtico en su estado actual ha pasado por diversos estadios constructivos ex novo y otros reconstructivos. Basta observar la inclinación del tejado único de la nave colateral y el pórtico para darse cuenta que en un primer momento tuvo una menor pendiente ${ }^{104}$. La colocación del pórtico se llevó por delante el alero con modillones que hemos citado anteriormente. Pero no voy a entrar en estas diversas trasformaciones, me limitaré a las dos fases que constituyen su longitud.

Las diferencias que se producen en los dos sectores del pórtico son muy acusados, no creo que se puedan explicar por un simple cambio de materiales reaprovechados. El primer tramo estaba constituido por siete arcos apeados en columnas reaprovechadas que presentan ciertas diferencias en modulo y altura. Los arcos iban trasdosados por una moldura que a su vez formaba un alfiz enmarcándolos todos. Como el muro sobre los arcos ha tenido que ser rebajado a la altura actual, adaptándose así a la nueva inclinación, ha sido necesario suprimir parte del mismo afectando al alfiz. En el segundo sector no hay ningún indicio de que existiese esta moldura. Los capiteles responden a otras proporciones. Pero la diferencia fundamental no reside tanto en que no se realice el alfiz, con ser esto fundamental, sino en que el dovelaje de la par-

\footnotetext{
${ }^{103}$ MARTÍNeZ TEJERA, El templo..., p. 140.

${ }^{104}$ Menor era la pendiente primera de la nave pues debía de adaptarse a la longitud y altura de los modillones. La altura del intercolumnio del pórtico fue pensada para recibir esta continuidad de pendiente. En un momento determinado, pero mucho después de acabado el pórtico, se aumento el ángulo de la pendiente obligando a rebajar la altura del intercolumnio del pórtico.
} 
te central (entre hombros) de los arcos del primer sector es totalmente diferente. Es evidente que este segundo sector ha sido realizado por un equipo de recursos rudos y sin ningún tipo de sentimiento estético. A todos estos nuevos recursos hay que añadir, al menos por lo que podemos apreciar en la excavación, un tipo de cimiento corrido que no podemos constatar en la otra parte.

Salta a la vista que el primer sector estaba formado por siete arcos, aunque el último hubo que rehacerlo al añadirle el segundo sector. Si rehacemos de forma simétrica la terminación de este pórtico de siete arcos podemos comprobar que este se cerraba casi sobre la misma línea de la porta chori (Lám. 28). Aunque carecemos de información suficiente para poder afirmar que este tipo de pórtico con siete arcos es el modelo que se seguirá en las primeras galerías porticadas del románico castellanoleonés, es evidente que coinciden en esta disposición simbólica o no. Pero dejando de lado esta mera especulación, es necesario que nos preguntemos ¿por qué el pórtico no alcanzó desde el primer momento todo el lateral del templo? La única galería lateral coetánea a esta, o poco anterior, que conocemos, es la de San Salvador de Valdediós. Aquí la galería no alcanza todo el frente meridional del templo porque se lo impide la sacristía. En las iglesias románicas, que carecen de las sacristías canónicas de la liturgia hispana, solo la presencia de un brazo del crucero puede impedir que la galería porticada se desarrolle a todo lo largo de las naves. En Escalada es evidente que no existió crucero, sin embargo es probable que existiera una sacristía o una construcción previa. Curiosamente la parte del muro de la iglesia que se corresponde con la ampliación del segundo sector ha sido rehecho totalmente, impidiendo así comprobar si aquí había una puerta que comunicase con una sacristía. En paralelo con el muro rehecho corre un cimiento de una gran potencia que no se explica solo por el intercolumnio que se construyó después sobre él. Por último quisiera hacer dos reflexiones sobre el pórtico: el material reaprovechado y la cronología.

Todas las columnas han sido reaprovechadas ${ }^{105}$. Los capiteles, con la excepción del $n^{\circ}$ 8, pertenecen, aunque con distintos tamaños, a un mismo tipo y una misma época. El hecho de que los capiteles del segundo sector sean más grandes y aparezcan cortados por su cara interna ha servido para que todos los estudiosos coincidan en señalar que han sido reaprovechados de otro lugar ${ }^{106}$. De esta manera lo lógico es pensar que, realizados en el siglo $X$, los del primer sector fueron colocados en su sitio, mientras que los del segundo se situaron en otra parte del edificio que actualmente no conocemos. Sin embargo tengo la impresión que incluso los capiteles que se colocaron en el primer sector son también reaprovechados. Esta afirmación se podría justificar por la diferencia de módulo y proporción existente entre ellos, sin embargo esto no me parece definitivo, mucho más significativo es como se adaptan las cestas a los muros. En el primer capitel (Lám. 29), apreciamos como la cesta ha sido esculpida totalmente y luego se ha amputado para adaptarla al muro al que se adosa. Esta solución es muy habitual en algunos edificios del siglo $X$, pero no sigue ninguna de las normas de la tradición romana perfectamente documentadas todavía en la arquitectura asturiana. Primera fórmula: la cesta se esculpe totalmente y luego se adosa sin

${ }^{105}$ Es posible que el capitel de la columna no 8 empezando por la parte occidental. Tampoco son reaprovechados los cimacios que no son de nacelas escalonadas.

${ }^{106}$ La forma de estar cortados indica que se debe a que ya habían sido reaprovechados anteriormente. La zafiedad del taller, la escasa sensibilidad estética del los patrocinadores o su penuria económica, tal vez todo ello, hizo que no tuvieran inconveniente alguno en colocarlos de manera tan zafia mostrando la rotura de la cesta. 
romperla al muro. En la iglesia de San Juan de Baños podemos ver como el material es reaprovechado manteniendo la forma de aparejar la columna al muro (Lám. 30). Para que este sistema funcione es necesario que el cimacio sea una pieza enteriza y con una parte entrega en el muro. Tal como es el cimacio reaprovechado de Escalada, donde se aprecia perfectamente que no se adapata correctamente por una cuestión de tamaño del cimacio y el modo de "entregarlo" en el muro. La segunda fórmula nos muestra la cesta con una parte lisa que se entrega al muro, tal como podemos contemplar en estos capiteles asturianos de San Tirso de Oviedo, Naranco y Gobiendes (Lám. 31, 32 y 33). No se entiende bien que los constructores del siglo $X$ realizasen unos capiteles completos excelentes para luego cortarlos tan burdamente. Por un lado, se trabajaba más de la cuenta, se aprovechaba mal el material disponible; y lo que es peor, se corría el riesgo de que al cortarlo se rompiese la cesta completa. Desde mi punto de vista, este modo de proceder sólo admite dos explicaciones: $1^{\mathrm{a}}$ ) los capiteles se labran en serie en un determinado taller y se venden, adaptándolos los compradores a las fábricas que están realizando; $2^{2}$ ) se trata de material reaprovechado. No creo en la primera explicación, pues basta ver el cimacio entrego de Escalada y el capitel que se le adapta para darse cuenta que no estaban pensados para combinarse. Pero además de todo esto, con la simple contemplación del deterioro de los capiteles se percibe que han sufrido múltiples roturas, aunque alguna pudiera tratarse de una "gamberrada pueril", la mayoría son fruto de derrumbes y ruina del edificio del que procedían. Gómez Moreno ha detectado como alguna de estas roturas fue rehecha colocando un añadido en el momento de su reempleo, tal como se aprecia en uno de los capiteles del pórtico
(Lám. 34) ${ }^{107}$ Lo que no tenemos resuelto es la datación que podemos dar a este material reaprovechado ${ }^{108}$.

Dejando a un lado el problema que hemos planteado de la escultura monumental, lo constructivo del pórtico nos permite hacer una propuesta cronológica. La forma de aparejar los arcos con un determinado tipo de dovelaje y el tratamiento con la moldura de alfiz, tanto en el paramento interno como el externo, señalan un espacio arquitectónico bien definido que pudiera corresponder al siglo $\mathrm{X}$, posterior a la consagración del año 913, aunque posiblemente en su inmediata continuidaad. Al desaparecer la construcción que impedía la mayor longitud del pórtico, se produjo la ampliación de éste. $\mathrm{Si}$, tal como pienso, se trataba de una sacristía al uso de la vieja liturgia hispana, esto se pudo producir en el tercio final del siglo XI. La forma descuidada y chapucera de su construcción podría coincidir con esta misma cronología, que tal vez se pudiera concretar con el epígrafe de restauración del ara (1088). Esta misma falta de calidad se empieza a detectar en el arco de Sábarico.

\subsection{Fases fundamentales de la construcción}

En la fábrica actual detectamos fases constructivas y trasformaciones de las

107 GÓMEZ MORENO, Iglesias mozárabes, p. 161. El tipo del ave reproducido en el remiendo recuerda el arte de los escultores que realizaron las obras decorativas del 913.

${ }^{108}$ De las dudas que surgieron en el debate sobre la comunicación de Domínguez Perela, según la cual se podría pensar en una fecha muy alta para estos capiteles, deberíamos replantearnos un nuevo sistema de estudio de estas piezas. Para este investigador las características de estos capiteles, aunque con grandes dudas, podrían corresponder a una plástica deudora de la cultura clásica, en un momento próximo a la segunda mitad del siglo VI" (DOMínGUeZ PERELA, "Los capiteles...", p. 71). Lo que si parecían tener claro todos los participantes en la cuestión (Palol, Yarza, Moralejo Ainaud, siguiendo trabajos de Schlunc, era que no tenían origen árabe) (Idem, pp. 77 - 85). 
mismas. No entraremos en el detalle de estas últimas y tan sólo nos limitaremos a identificar las fases más significativas, poniéndolas en relación con las referencias documentadas que tenemos. Lo más significativo es el aprovechamiento continuado de materiales expoliados para más del noventa por ciento del material decorativo monumental.

Salvo que el epígrafe que hemos estudiado detenidamente no se refiera el monasterio de San Miguel que conocemos en la actualidad, cosa que no ha sido cuestionada por nadie, el antiguo templo anterior a la llegada de los monjes cordobeses tiene que encontrarse bajo la superficie del actual. ${ }^{109}$. Sin embargo, desde mi punto de vista, las excavaciones de Larren han dejado muy claro que bajo esta iglesia no hay huellas de ningún otro templo cristiano, aunque para ella sí (Lám. 35). Coincido con su opinión de que se ha encontrado un nivel conformado por "un conjunto de habitaciones, de planta rectangular, que conservan en pie el arranque de sus muros, desde los niveles del suelo de opus signinum $(\text { siglos IV }-\mathrm{V})^{\prime \prime}$. Después se producirá una reutilización de este asentamiento en un momento posterior que debe situarse entre los siglos VI y IX, justificado por pequeñas reformas y los enterramientos de época visigoda, aunque no define ningún tipo de templo ni nada que se le parezca. Concluye diciendo que " es la tradición de un lugar sacralizado lo que lleva a ubicar el monasterio mozárabe en el actual San Miguel de Escalada, construido en la primera mitad

\footnotetext{
${ }^{109}$ Documentalmente no consta ningún traslado. La continuidad en uso de la iglesia monasterial está perfectamente acreditada por los testimonios epigráficos y por la práctica cultual hasta la exclaustración. La ampliación con una capilla románica en su costado meridional corresponde a una práctica habitual para capillas de patronato o, muy especialmente, de carácter funerario. En todo caso esta parte del edificio no va a ser estudiada aquí.
}

del siglo $X$, que progresivamente va adquiriendo importancia“. Prueba de esta importancia progresiva es la ampliación románica de fines del siglo $\mathrm{XI}^{110}$.

Veamos cual es mi interpretación de la información arqueológica y la suministrada por la historia. Una de las pocas cosas indiscutibles del epígrafe es que el viejo edificio está incluido en el templo consagrado en el 913, que por entonces sólo sufrió una renovación que afectó a lo decorativo. Los indicios arquitectónicos encontrados por Larren por la orientación de sus muros y la organización de sus espacios no responden a ningún templo; sin duda, como ella indica, son romanos. Los elementos visigodos se reducen a tres tipos: restos de un cimiento, muy indefinidos que parecen una reforma de una de las habitaciones romanas; fragmentos de cerámica y varios sepulcros $^{111}$. Lo más significativo son los sepulcros denominados por ella visigodos. Aparecen perfectamente orientados y alineados con la misma dirección canónica del templo, se diría que han sido dispuestos de acuerdo con un hipotético templo coetáneo cuya superficie respondiese a la misma orientación que el denominado mozárabe por Larren. Dos restos metálicos parecen el material arqueológico más representativo: un "broche de cinturón" de lengüeta triangular, datado a fines del siglo $\mathrm{VI}^{112}$; en el enterramiento del ábside meridional apareció como ajuar "una pequeña jarrita, de cuerpo globular y fondo plano, con huella de un asa lateral, rota en el inicio del cuello,

\footnotetext{
110 LARREN, “Excavaciones arqueológicas..", p. 121.

111 Ídem, p. 115. LARREN, "San Miguel de Escalada... . El material cerámico es muy pobre y casi inclasificable por sus características inerciales:"Cuantitativamente es el grupo menor....estampada de imitación paleocristiana, con decoración a peine y comunes" (Ídem, p. 229).

112 Ídem p. 234.
} 
de pasta gris, factura tosca y fuego reductor $^{\prime \prime 13}$.

¿Dónde está el templo visigodo de San Miguel, grande o pequeño? En ninguna parte. En la superficie interna no hay un solo rastro de muro o de cimiento que se le pueda atribuir. Larren ha seguido todas las líneas de cimiento del edifico, tanto de muros como de soportes. Solo los muros sur, con un una zapata corrida de hormigón, y el occidental con la aplicación de micropilotes no han permitido el estudio de sus cimientos ${ }^{114}$. Las columnas tienen zapatas cuadradas como cimiento siguiendo una de las tradiciones tardorromanas hispanas que tuvieron su continuidad en la primera fase constructiva de la mezquita de Córdoba y en otras muchas obras cristianas "prerrománicas". Solo aparecerá un cimiento corrido en la última ampliación del pórtico lateral según una fórmula más difundida a partir del siglo XI, y de la que ya nos hemos ocupado.

Al no reconocerse en las excavaciones arqueológicas restos de otro templo, lo lógico es pensar que no se manifiestan porque están asumidas en la fábrica que contemplamos en la actualidad. Es incontestable que, según demuestra la arqueología, no hay posibilidad de un templo de una nave que se pudiera ampliar a tres, o de uno más corto que se prolongase hacia el este o el oeste según los usos utilizados para este tipo de ampliación en la arquitectura templaria medieval. De esta manera, sólo conozco una posibilidad lógica: a excepción del pórtico lateral, el edificio debería responder en esencia al mismo tipo planimétrico que todavía pervive, con introducción de ciertos replanteos en la zona de crucero y ábsides, y, con toda seguridad, en

\footnotetext{
113 LARREN, "Excavaciones arqueológicas..", p. 115.

114 Ídem, p. 120 y LARREN, "San Miguel de Escalada..., pp. 221 y 222.
}

la sobreestructura mural que ya hemos venido comentando anteriormente. ${ }^{115}$

Cuando llegó el abad Alfonso, se conservaba el bloque del templo, casi con toda seguridad de tres naves. Los dos intercolumnios con los capiteles que hemos señalado son indiscutiblemente de esta primera parte ${ }^{116}$. Los muros de cierre y sus puertas presentan las remodelaciones $\mathrm{y}$ trasformaciones que hemos apuntado. Sobre el actual sobrealzado en ladrillo como una obra que sustituye a otra anterior ya hemos hablado anteriormente

Las obras anunciadas en el epígrafe se refieren a una remodelación de la cabecera, especialmente la zona del coro de los monjes y la puerta del coro (iconostásis, Lám. 37). La ampliación del número de los monjes, así explicitado en el epígrafe, requería un mayor espacio para su ubicación en el lugar reservado para ellos en el templo (coro). Como también indica el epígrafe, de manera indiscutible, se trata de una obra especialmente dedicada a lo ornamental: Capiteles nuevos de esta parte y relieves/cancel ${ }^{117}$. De la remodelación sufrida en la parte tripartita del coro existen indicios arqueológicos bien documentados. El pilar septentrional de la puerta del coro contaba con un codillo que no tuvo correspondencia con su parejo meridional, ni con el oriental, indicio claro de un proyecto en altura del que se desistió en pleno proceso de remo-

-

${ }^{115}$ Para Ramón CORZO es evidente que el perímetro del actual edificio y sus proporciones se corresponden con el mismo edificio visigodo restaurado por los mozárabes (Visigótico y prerrománico, Madrid, 1989, p. 91).

${ }^{116}$ Conviene no olvidar que se podía sustituir en cualquier momento un capitel por otro. A este respecto, téngase en cuenta que, con cimbrear las arcadas y apuntalar el dovelaje, esta operación era posible.

${ }^{117}$ Pese a que se ha querido señalar como modelo unos aspectos icónicos vegetales muy estilizados en el mundo andalusí, salta ala vista que lo más próximo son obras leonesas datadas en el siglo $X$ que siguen exactamente modelos romanos de la misma zona. 
delación (Láms. 37 y 38) ${ }^{118}$. Para los canceles recién hechos, según comentamos, se dispone una estructura que le servirá de soporte constituida por una base de ladrillos unidos con $\mathrm{cal}^{119}$. Embellecido y reformado así el coro, se procedió también a arreglar el ábside central, dotándolo del friso relicario similar a la puerta del coro, posiblemente sustituyendo las pilastras del arco triunfal con columnas reaprovechadas ${ }^{120}$, cambiando el suelo y sustituyendo el altar primitivo donde se dispondría el ara con características plásticas similares a las de los canceles ${ }^{121}$. El tratamiento de sillares de la cabecera, con el característico tipo de modillón alto y el mantenimiento del friso de esquinillas que reaparecerá en la fábrica de ladrillo, será la fase siguiente, anterior a las obras de la segunda mitad del siglo XI que son de una gran pobreza que no se puede corresponder con el coste de esta sillería.

La labor de embellecimiento que tanto alaba la inscripción se debe a las hermosas placas de cancel (Lám. 39, 40 y 41) que delimitaban el espacio del coro. Motivos icónicos y factura corresponden a la vieja

118 ¿Buscando el apoyo para una arista o arco crucero de un posible cimborrio? Las fotografías del siglo XIX nos muestran como el frente del pilar había llegado mutilado (Fig. 39) ( José Ramón SORALUCE BLOND, Historia de la arquitectura restaurada de la Antigüedad al Renacimiento, A Coruña, 2008, pp. 250 - 252 y fig. 217)).

${ }^{119}$ Para Larren se trataría de una obra realizada sobre la iglesia mozárabe ya construida (LARREN, "Excavaciones arqueológicas..", p. 117), según estoy explicando en realidad es una obra sobre la iglesia visigoda.

${ }^{120}$ Gómez Moreno ha señalado como la solución dada a las jambas y columnas del arco del ábside central es una remodelación del proyecto original (Gómez Moreno, Iglesias Mozárabes, p. 146).

${ }^{121}$ Aunque Larren señala como mozárabe el primer altar (LARREN, "Excavaciones arqueológicas..", p. p. 117), es evidente que por su colocación directamente sobre las obra romana tiene que corresponder al edificio hispanogodo, o a una restauración de acondicionamiento del primer momento del asentamiento de los monjes. plástica tardorromana que tuvo en tierras leonesas muestras tan expresivas que no dejan lugar a la duda del modelo. Como lo icónico y lo técnico resultan prácticamente indatables, basta una simple comparación con piezas de los yacimientos leoneses, algunas de ellas conservadas en los almacenes del Museo de León, lo procedente de Escalada podría ofrecernos dudas. Sin embargo la comparación con a decoración de las aras y otras piezas leonesas perfectamente datadas, nos permiten fijar con absoluta precisión su cronología en las obras del 913. En la línea de cierre de las naves con el coro, los del pórtico del mismo podrían haber sido hechos entonces, mientras que los restantes de esta línea son también reaprovechados. Los frisos corridos sobre el pórtico y sobre el arco triunfal (yeso) también corresponden a esta fase de embellecimiento.

Del pórtico, lo más importante, no son las fases del proceso arquitectónico, que creo que están perfectamente definidas, sino el origen de los capiteles y la cronología de las diferentes reutilizaciones de los mismos hasta que se colocaron definitivamente en Escalada.

Sobre los capiteles haré un último comentario, incidiendo en alguno de los aspectos ya comentados. No quisiera que mis palabras parezcan una crítica despreciativa hacia quienes los han estudiado, pues en realidad sus esfuerzos son muy meritorios. Sinceramente, son muy pocos los capiteles de los siglos IV al XI que podamos catalogar con precisión. Muy a menudo se olvida que a lo largo de todo el período continuamente se reaprovechan las columnas completas o parte de ellas. A veces en este lapso de tiempo se reaprovechan una y otra vez. Basta leer los comentarios que se hacen al analizarlos para darse cuenta que no hay argumentos sólidos, sólo coincidencias icónicas o estilísticas, que tiene su origen en el arte tardorromano y su 
"epigonísmo", que siguió produciendo formas similares a todo lo largo de la vieja geografía romana y su secuencia cultural. Esto supone que capiteles a miles de kilómetros de distancia se parezcan, sin que para ello tenga que existir una relación directa. Son frutos de una misma cultura, que desaparecida la estructura de poder que la unifica, pueden seguir teniendo un desarrollo más o menos paralelo. Dicho esto no se entiende comentarios tan vacíos de significado como bizantinos, bizantinizantes, sirios, armenios, etc ${ }^{122}$. Creo que todos estamos de acuerdo que debemos distinguir dos grandes grupos de capiteles. Los del interior y los del pórtico. Los del interior son todos reaprovechados de edificios diferentes, muy pocos son los que se pueden agrupar en series. Parece que los que hemos señalado para la zona del pórtico del coro son los únicos que corresponderían a la obra de 913. Todos los dispuestos en el pórtico meridional responden a una misma tipología y a pesar de su distinto tamaño son de un mismo monumento y época, aunque en Escalada no hay ninguna duda que han sido reaprovechados.

${ }^{122}$ Lo último que se ha dicho sobre los capiteles de Escalada me parece que no ha progresado sobre lo que acabo de comentar:, salvo que el autor considere que los de la obra leonesa y los modelos propuestos no tienen ninguna relación directa, ni de subordinación reproductiva, sino simplemente herederos de viejos prototipos más antiguos y universales que si pudieron inspirar a unos y otros : " Consecuentemente, podemos dividir los capiteles de la iglesia de San Miguel de Escalada en dos grupos, aquéllos situados en el interior que se relacionan claramente con producciones italianas del s. VIII-IX dC y aquéllos situados en el pórtico que, y a pesar de presentar algunas similitudes con capiteles coptos de Egipto, podemos vincular con las producciones lombardas del s. VIII-IX dC. De hecho, es este segundo modelo de capitel el que va a ser reproducido, con pequeñas variantes, en la mayoría de edificios mozárabes de esta zona" (DOMINGO MANGAÑA, Capiteles Tardorromanos... p. 340).

\section{CONCLUSIÓN}

Como hemos comentado reiteradamente a lo largo del trabajo, estas páginas sólo pretenden plantear una serie de conclusiones a partir de lo que conocemos hasta la actualidad. Deberán ser tenidas como provisionales hasta que se puedan realizar estudios y catas del edificio que permitan verificar cuestiones decisivas para su comprensión. Los aspectos más significativos los podríamos resumir en los siguientes puntos:

$1^{\circ}$ El viejo edificio de San Miguel que encontró el abad Alfonso era un templo de planimetría similar al que contemplamos en la actualidad. Realizado sobre una obra romana y con material de acarreo, especialmente las columnas.

2o El abad Alfonso limpió el edificio y debió acomodar la zona del ábside central con un altar para celebrar. Posiblemente la pervivencia del primer altar, le permitiese reconocer la advocación primitiva (San Miguel).

$3^{\circ}$ La supuesta ampliación de 913, no fue en superficie edificada, sino claramente en los elementos ornamentales y de adecuación del coro al aumento del número de los monjes, así como los altares. En la mayor parte de los capiteles que cierran el coro, los canceles y las aras denuncian un mismo taller y realización nueva.

$4^{0}$ Se remodeló la cabecera con la excelente sillería y el alero.

$5^{\circ} \mathrm{Al}$ mismo tiempo que la remodelación del 913 o en su secuencia se realizó el primer pórtico meridional, el de los siete arcos.

$6^{0}$ Todas estas obras, a pesar del reaprovechamiento de la mayor parte de la escultura monumental, denuncian un cierto poder económico en progresión. Sin embargo lo que se realiza después, hasta la 
aparición de las obras románicas propiamente dichas, el monasterio debió pasar por un periodo de crisis. Las características de sus obras así como la grosera chapucería de los reaprovechamientos así parecen confirmarlo.

$7^{\text {o }}$ Salvo los capiteles del iconostasio y alguno suelto, todos, incluidos los del pórtico, corresponden a material reaprovechado de obras anteriores. Claramen-

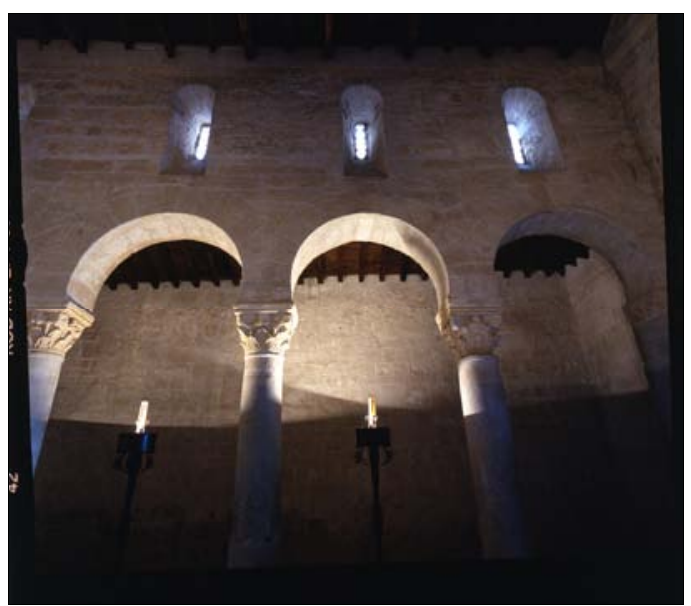

- Lám. 1. San Juan de Baños. Intercolumnio de la nave central. te tardorromanos. Los que son similares a los de Lebeña o Peñalba necesitan un estudio, pues lo que se ha afirmado de ellos hasta ahora carece de coherencia. Sinceramente podrían ser realizados en un mismo taller en serie y después colocados bárbaramente cortados en donde se encuentran en la actualidad. Tampoco me extrañaría, incluso me parece lo más probable, que perteneciesen a un expolio de un gran conjunto monumental hoy desconocido.

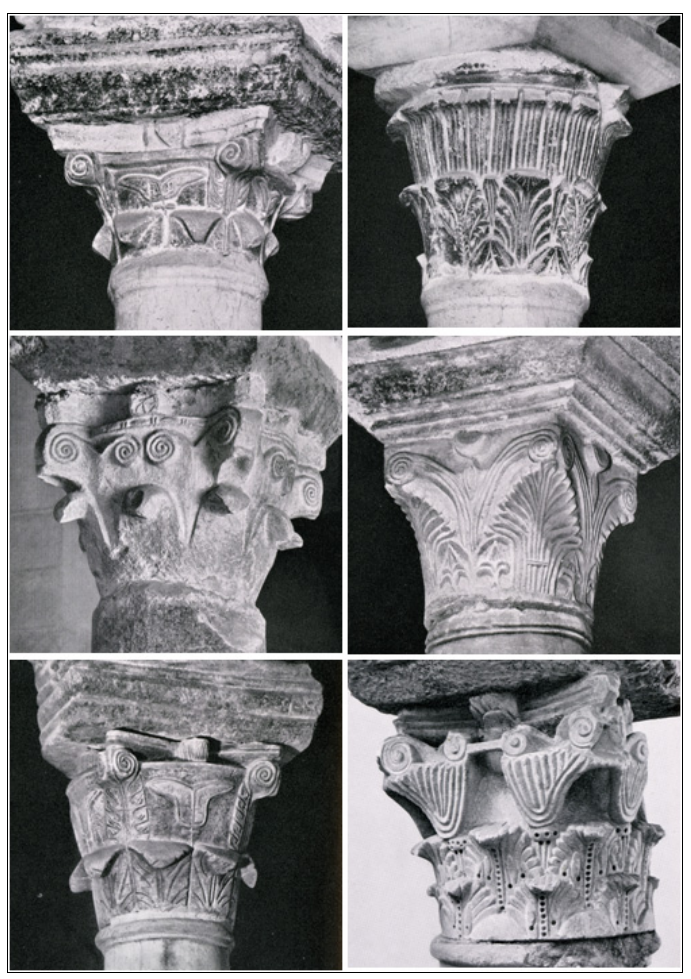

- Lám. 2. Capiteles reaprovechados de la primera fase de la Mezquita de Córdoba. 


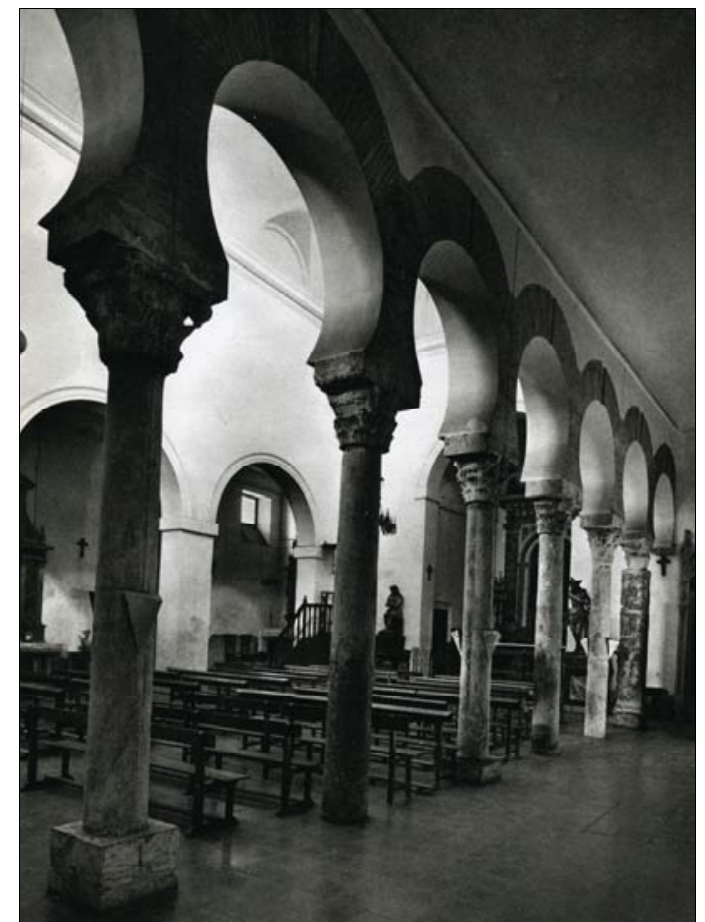

- Lám. 3. San Salvador de Toledo. Intercolumnio de la antigua mezquita.

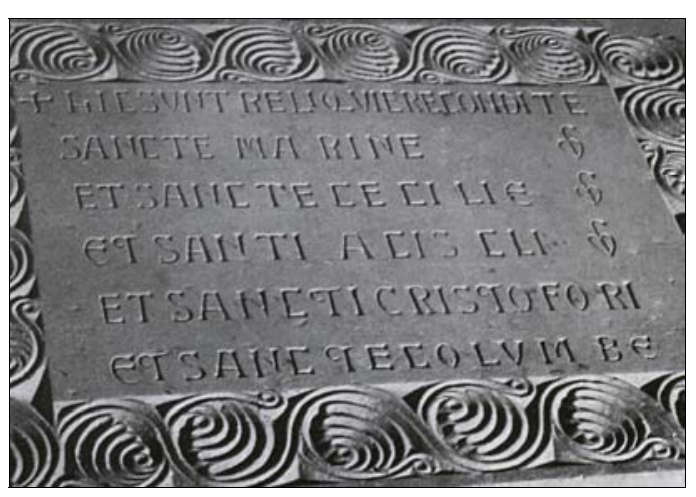

- Lám. 6. San Miguel de Escalada. Detalle del ara del ábside septentrional.

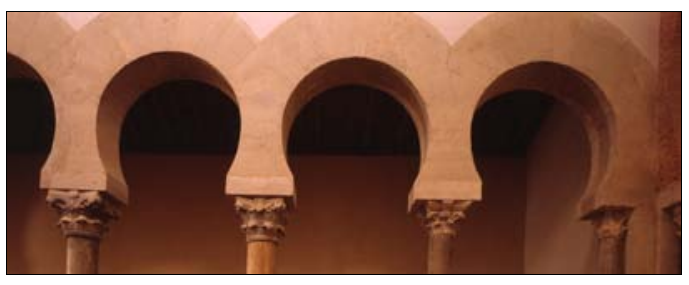

- Lám. 4. San Cebrián de Mazote. Detalle de uno de los intercolumnios.

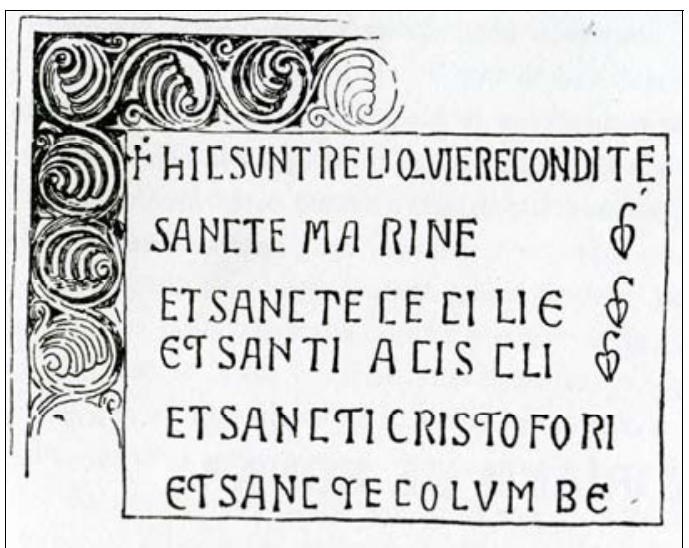

- Lám. 5. San Miguel de Escalada. Croquis del ara del ábside septentrional (Gómez Moreno).

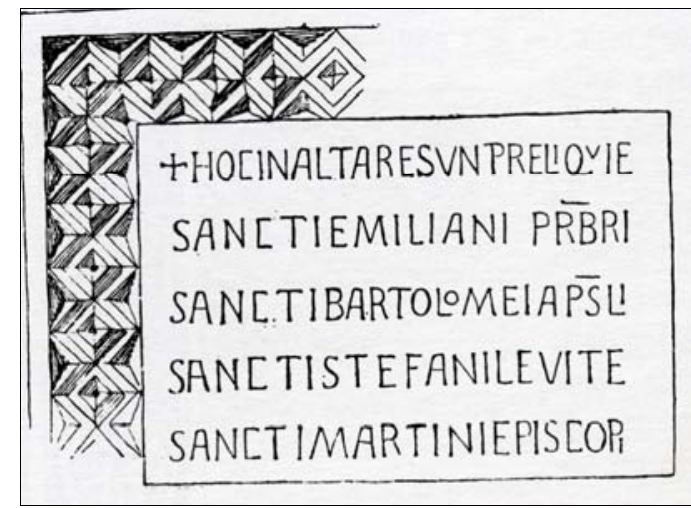

- Lám. 7. San Miguel de Escalada. Croquis del ara del ábside meridional (Gómez Moreno). 


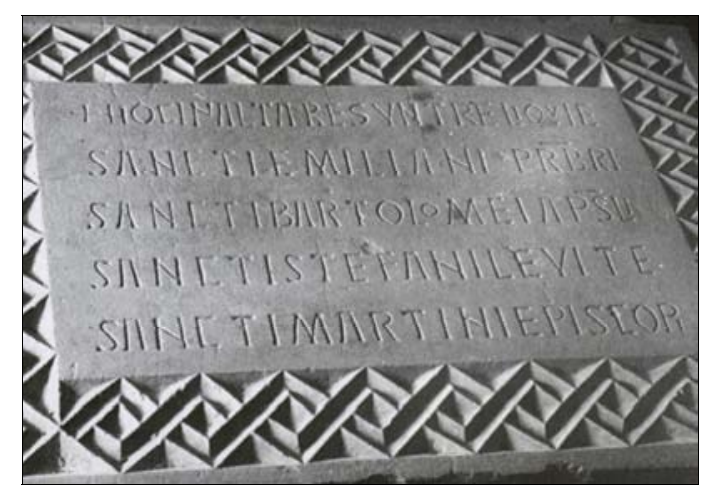

- Lám. 8. San Miguel de Escalada. Detalle del ara del ábside meridional.

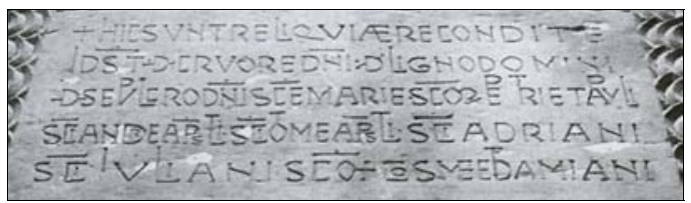

- Lám. 10. San Miguel de Escalada. Detalle del ara del ábside central.

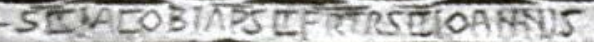

- Lám. 12. San Miguel de Escalada. Detalle del ara del ábside central con el epígrafe de Santiago.

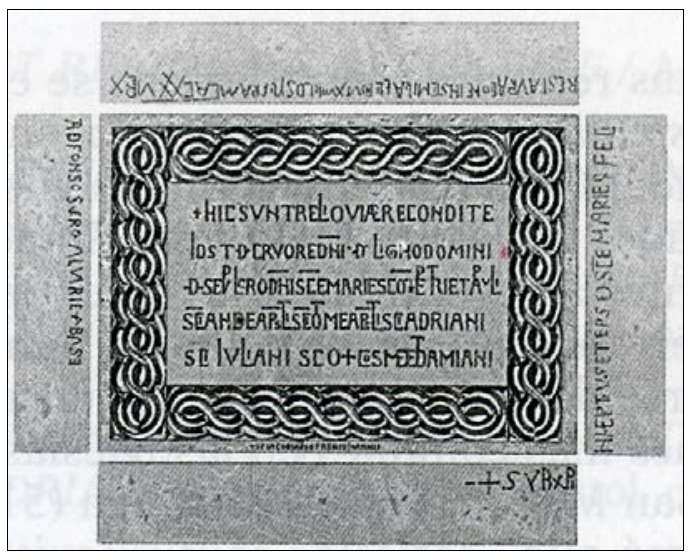

- Lám. 13. San Miguel de Escalada. Ara del ábside central con el desarrollo de las inscripciones (Monumentos Arquitectónicos Españoles)

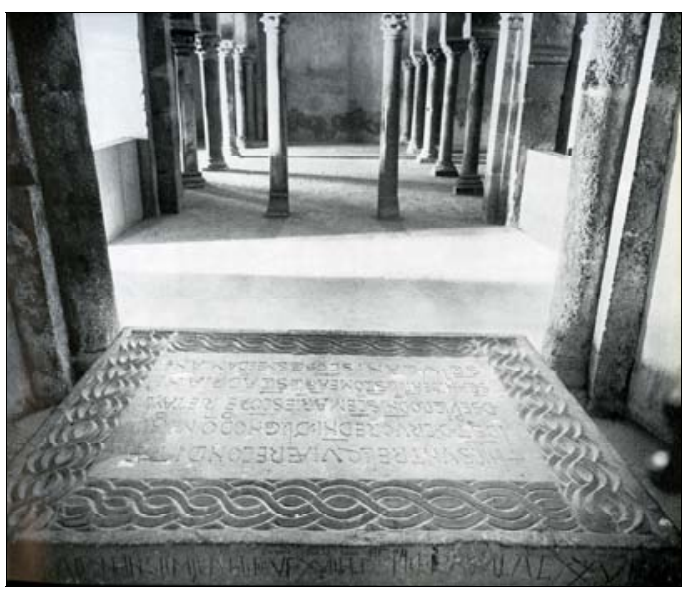

- Lám. 9. San Miguel de Escalada. Ara del ábside central desde ka cabecera.

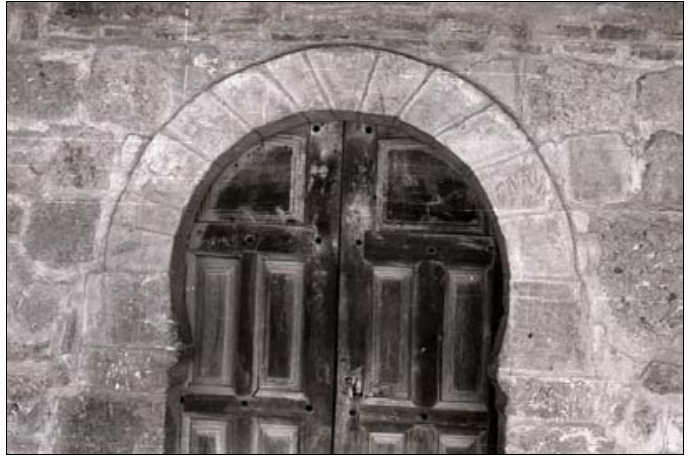

- Lám. 11. San Miguel de Escalada. Puerta meridional, conocida como arco de Sabarico.

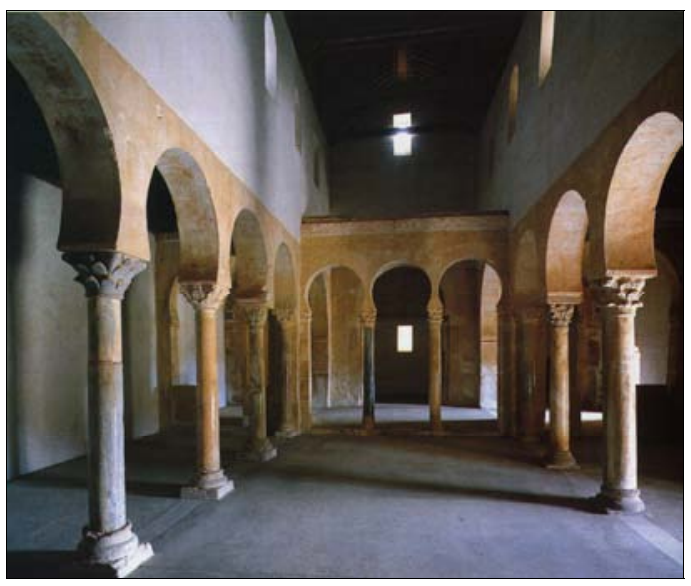

- Lám. 14. San Miguel de Escalada. Nave central con el pórtico del coro al fondo. 


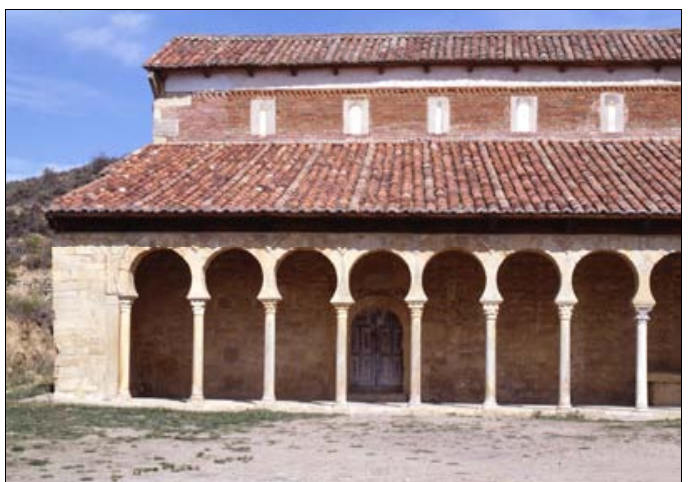

- Lám. 15. San Miguel de Escalada. 7 Arcos occidentales del pórtico meridional.

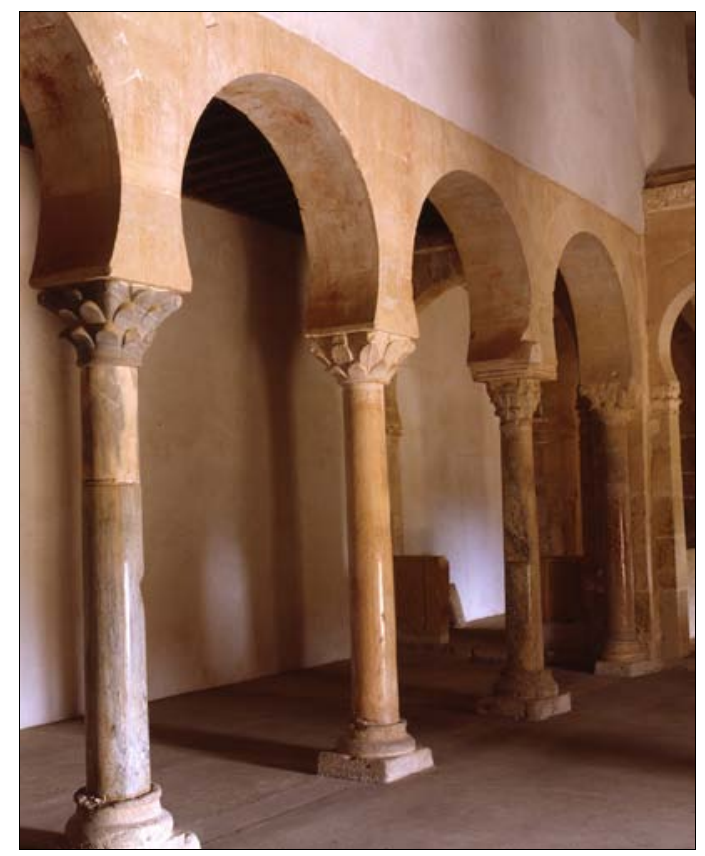

- Lám. 17. San Miguel de Escalada. Detalle del intercolumnio septentrional.

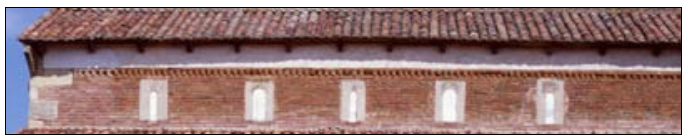

- Lám. 19. San Miguel de Escalada. Muro de ladrillo meridional de la nave central.

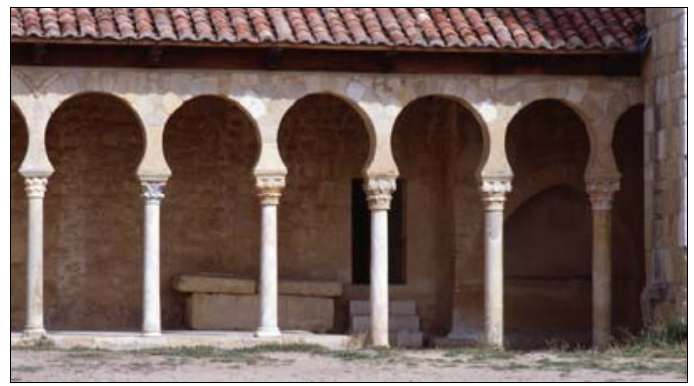

- Lám. 16. San Miguel de Escalada. Ampliación del pórtico meridional.

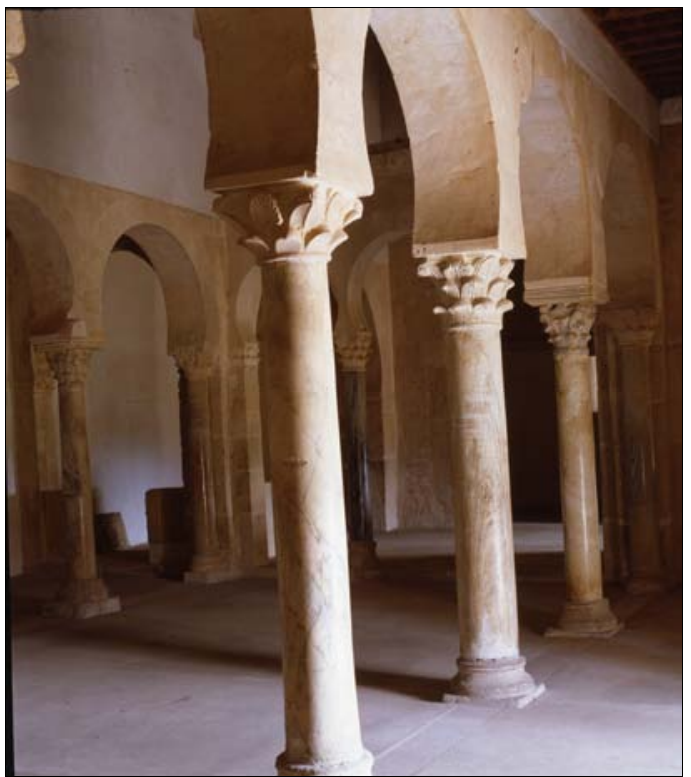

- Lám. 18. San Miguel de Escalada. Detalle del intercolumnio meridional.

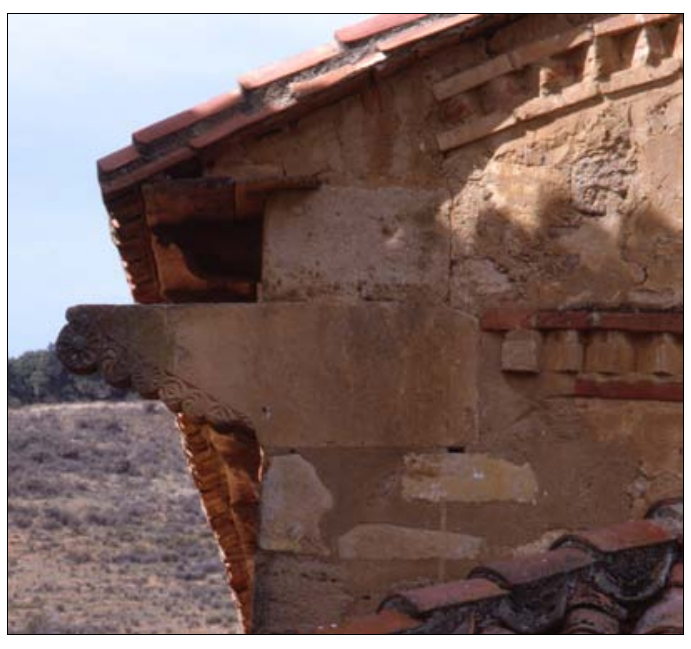

- Lám. 20. San Miguel de Escalada. Angulo sureste de la nave central.. 


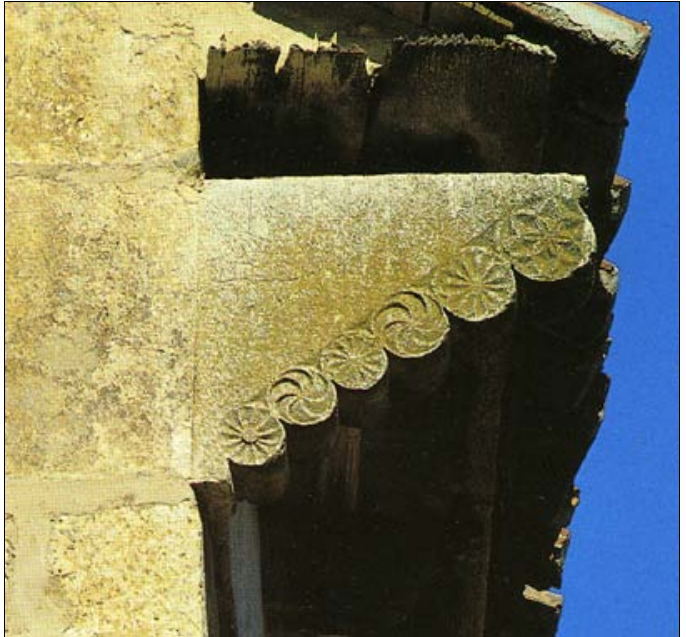

- Lám. 21. San Miguel de Escalada. Modillóm del extremo occidental de la nave central.

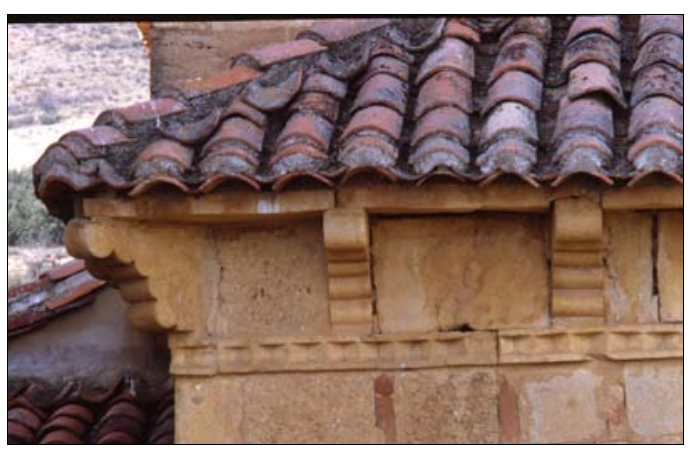

- Lám. 23. San Miguel de Escalada. Detalle del alero del ábside central

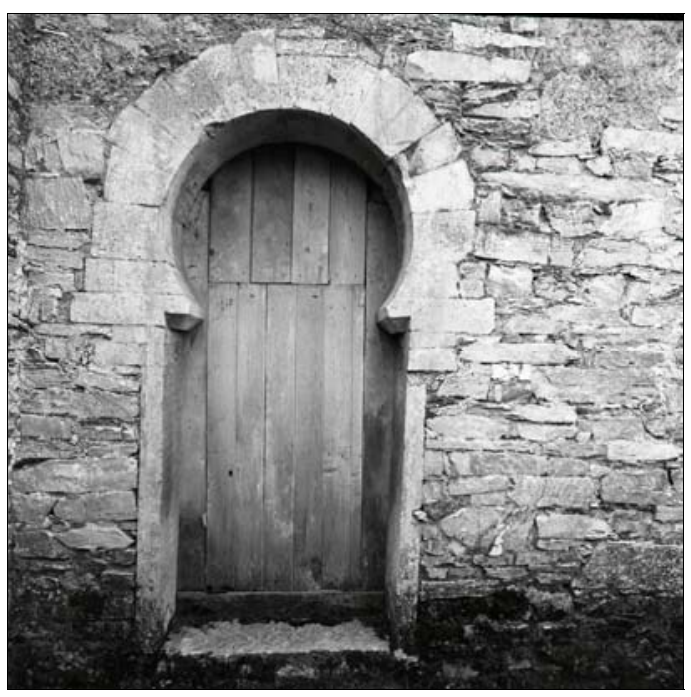

- Lám. 25. Santiago de Peñalba. Puerta lateral.

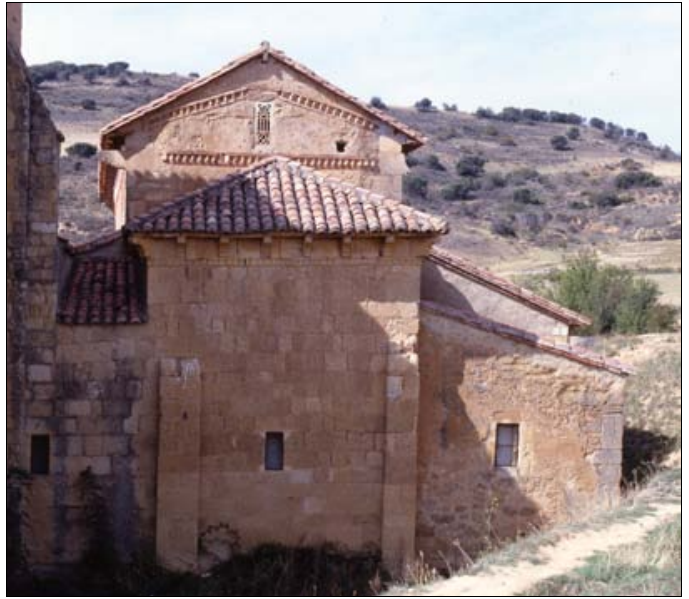

- Lám. 22. San Miguel de Escalada. Cabecera del templo.

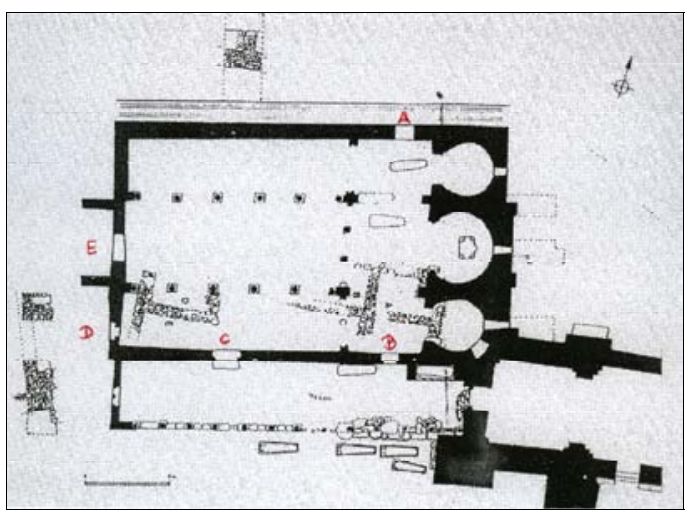

- Lám. 24. San Miguel de Escalada. Plano de las excavaciones (Larrén). Indicación de las puertas

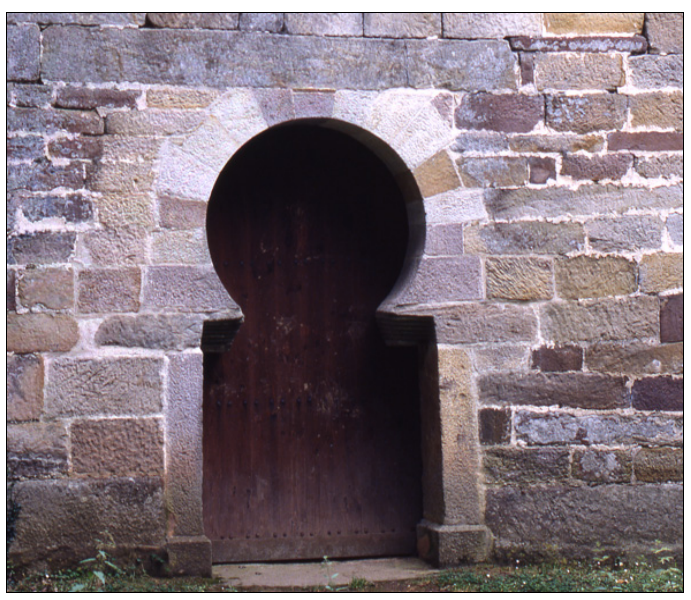

- Lám. 26. San Román de Moroso. Puerta lateral 


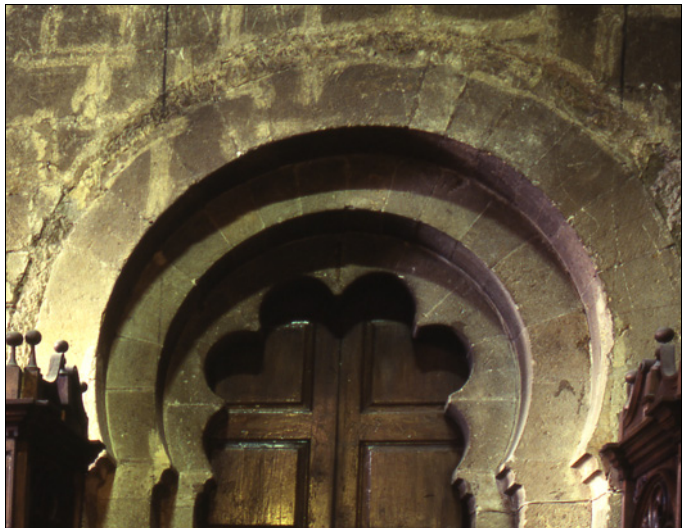

- Lám. 27. San Isidoro de León. Puerta occidental

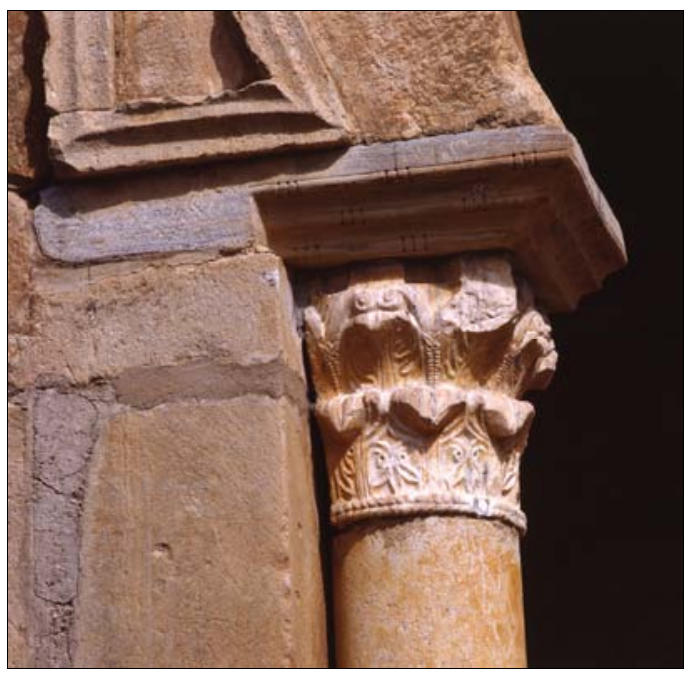

- Lám. 29. San Miguel de Escalada. Primer capitel del pórtico meridonal).

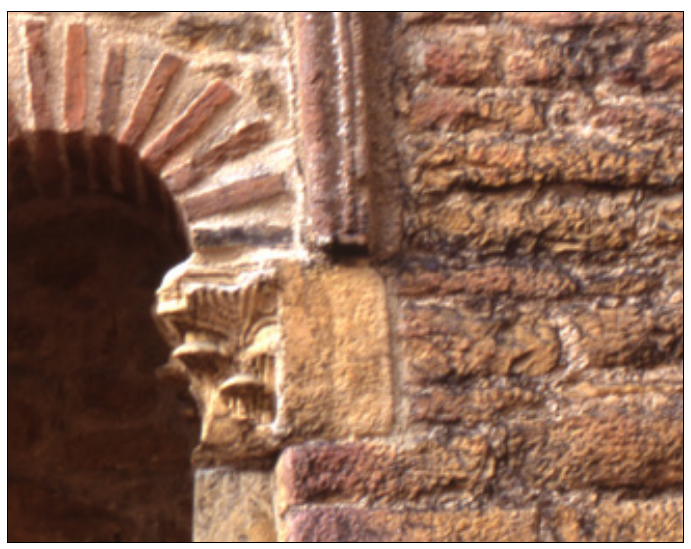

- Lám. 31. San Tirso de Oviedo. Detalle de la ventana).

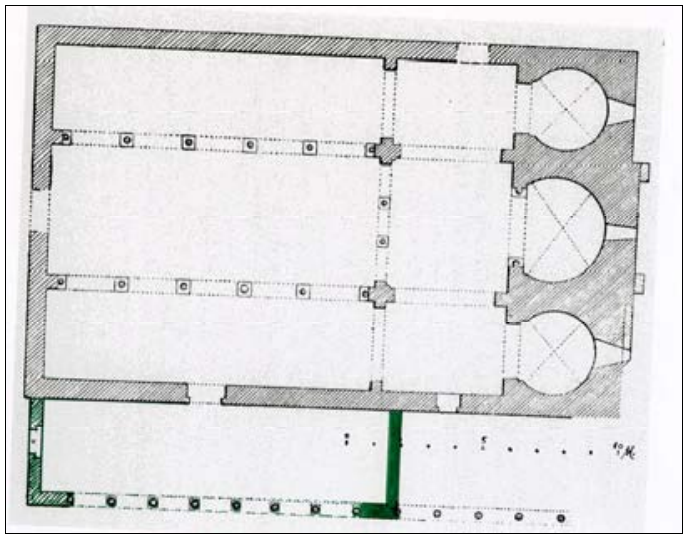

- Lám. 28. San Miguel de Escalada. Planta según Gómez Moreno, con indicación de la primera fase del pórtico (Bango).

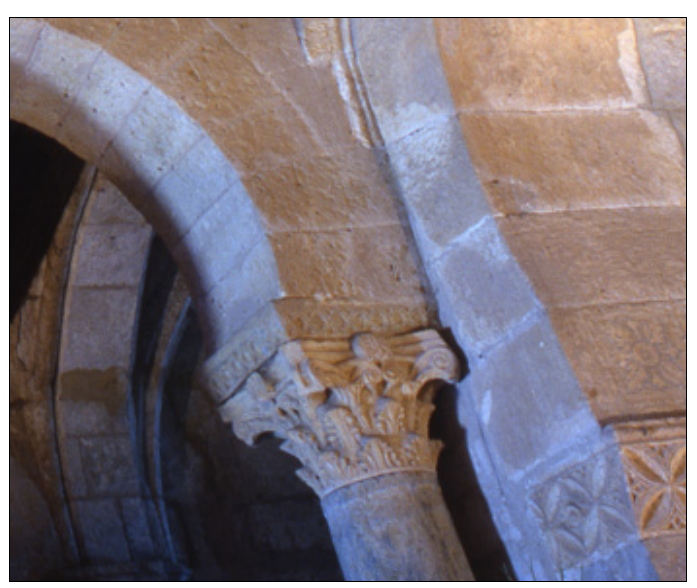

- Lám. 30. San Juan de Baños. Detalle del intercolumnio septentrional. 


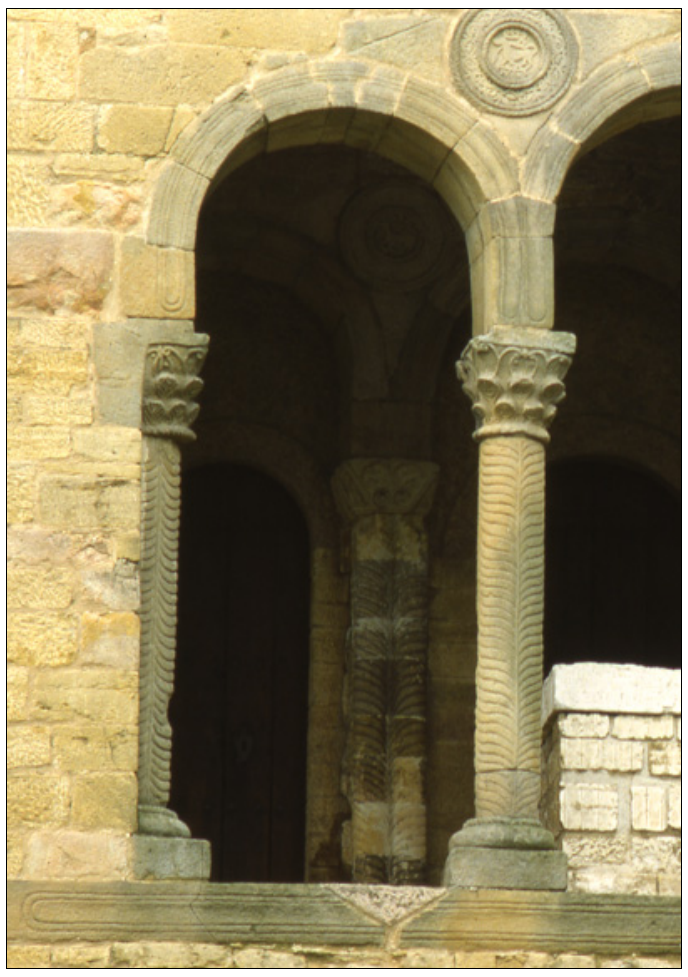

- Lám. 32. Santa María de Naranco. Detalle del gran ventanal.

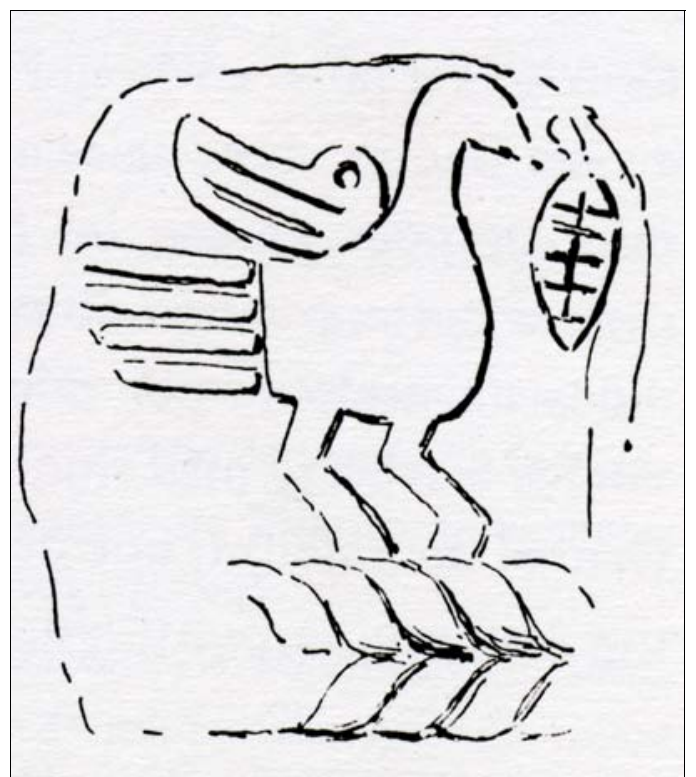

- Lám. 34. Remiendo de un capitel del pórtico meridional según Gómez Moreno.

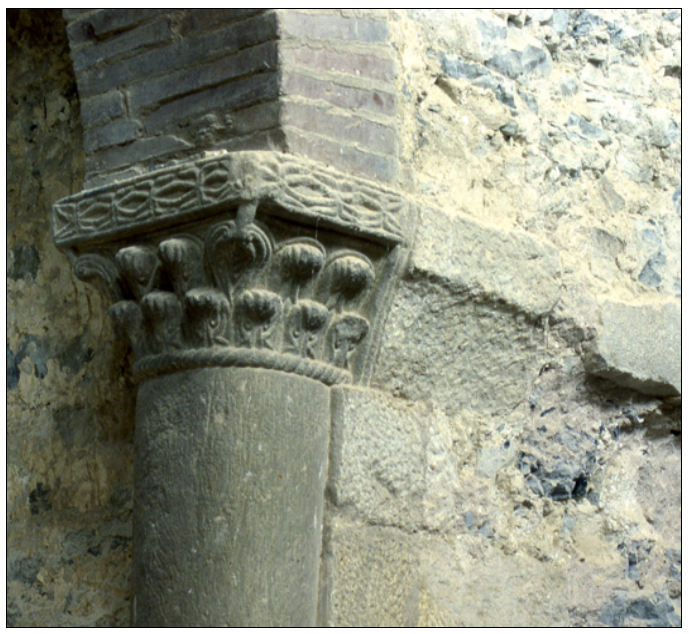

- Lám. 33. Santiago de Gobiendes. Capitel.

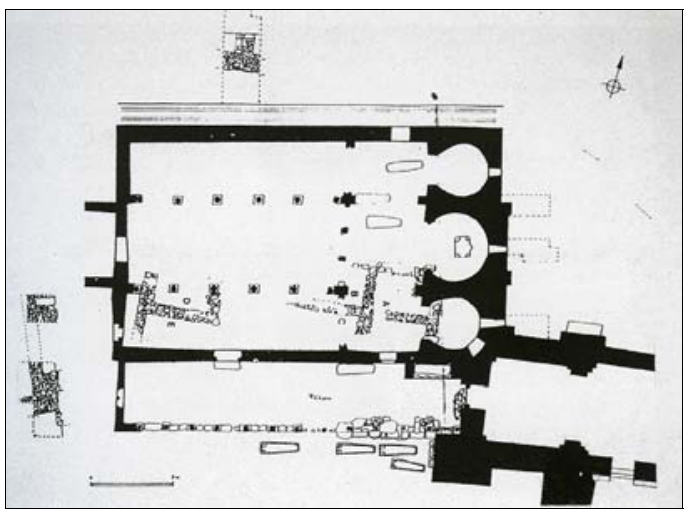

- Lám. 35. Plano de las excavaciones de San Miguel de Escalada (Larrén).

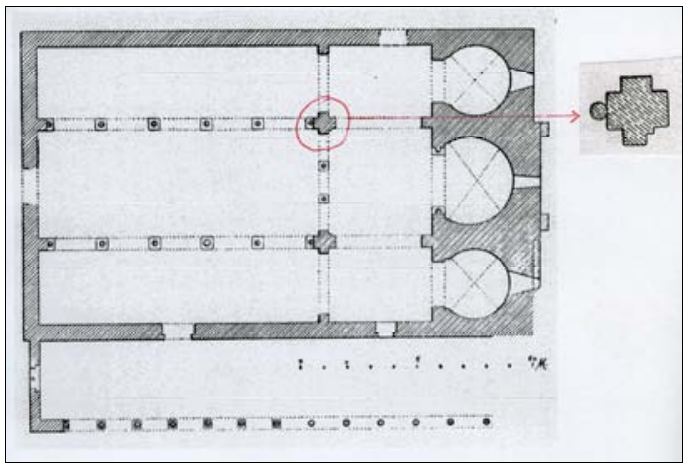

- Lám. 36. Plano de San Miguel de Escalada con el detalle del codillo del pórtico del coro (Gómez Moreno). 

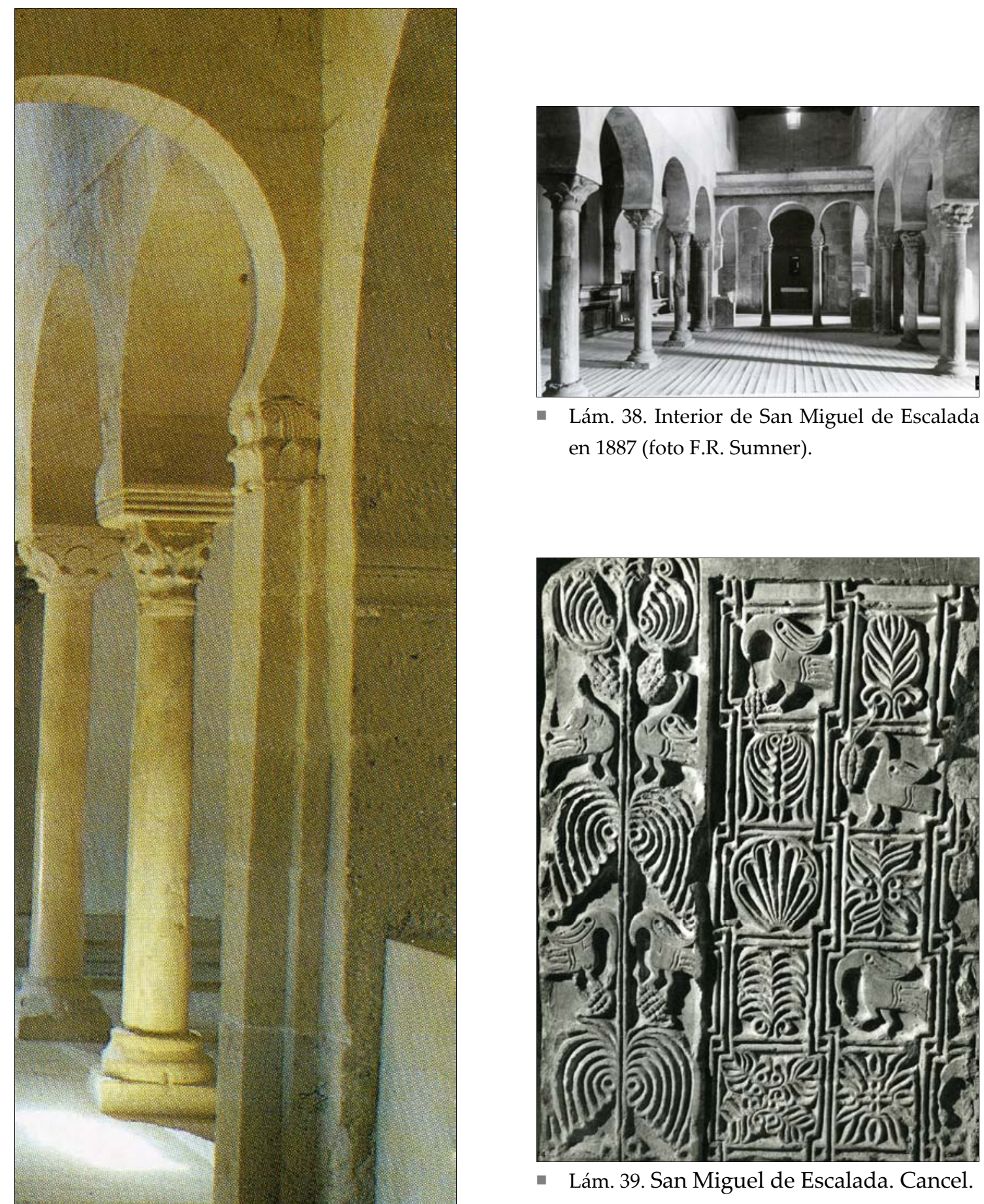

- Lám. 38. Interior de San Miguel de Escalada en 1887 (foto F.R. Sumner).

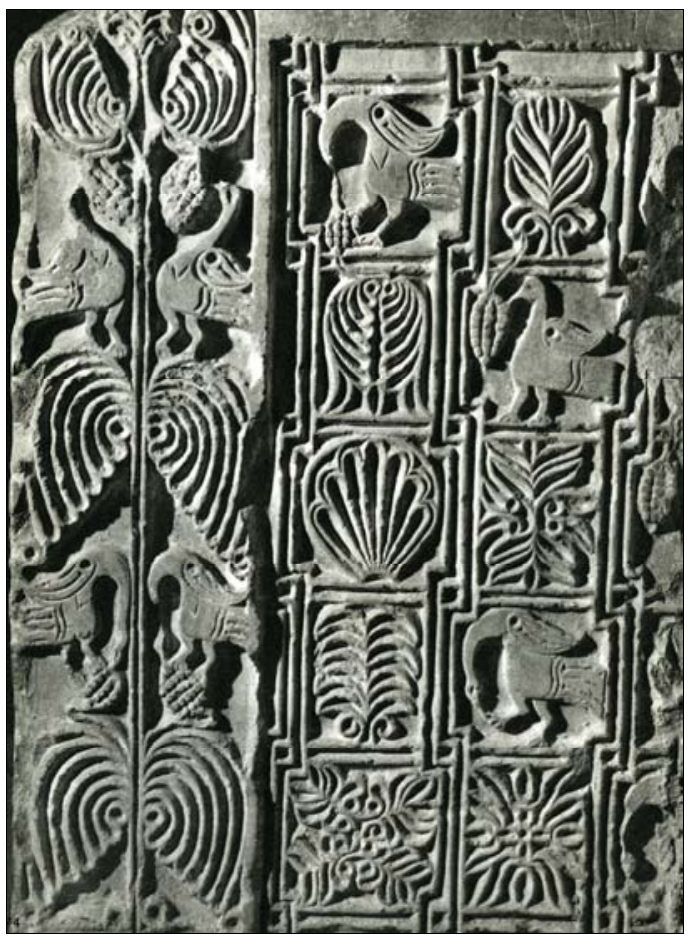

- Lám. 39. San Miguel de Escalada. Cancel.

- Lám. 37. Fotografía de detalle de la figura anterior 


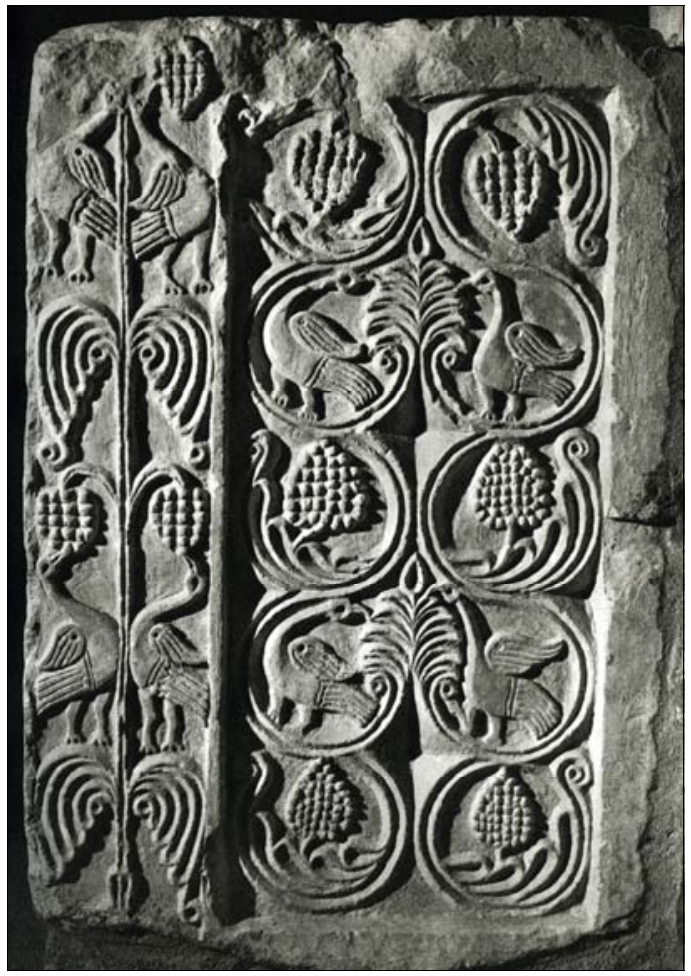

- Lám. 40. San Miguel de Escalada. Cancel.

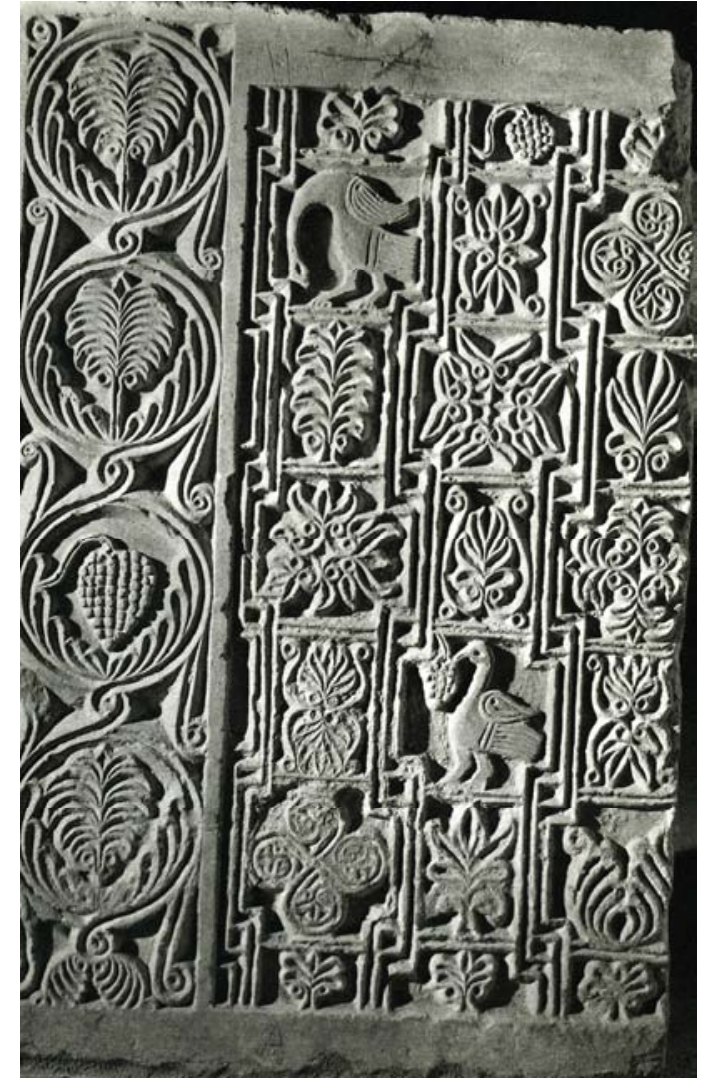

- Lám. 41. San Miguel de Escalada. Cancel. 